\title{
Comparative Crystal Field Studies II. Nickel(II) and Copper(II) Complexes with Polydentate Ligands and the Behaviour of the Residual Places for Co-Ordination
}

\author{
CHR. KLIXB ULLJ JRGENSEN
}

Chemistry Department A, Technical University of Denmark, Copenhagen, Denmark

\begin{abstract}
The complexes of nickel(II) and copper(II) with ethylenediaminetetraacetate, nitrogentriacetate and $\beta, \beta^{\prime}, \beta^{\prime \prime}$-tris(ethylamino)amine have one or more residual places left for co-ordination. The absorption spectra of such complexes containing either water, ammonia, ethylenediamine, glycinate or cyanide were determined. The wavenumbers of the bands illustrate the regular behaviour of paramagnetic octahedral nickel(II) complexes, whereas the intensities vary. Some copper(II) complexes are much more tetragonally distorted than others. The "chelate" effect in formation constants is not only due to the different dependence on dilution of the degree of formation of polydentate ligands' complexes, but can be estimated from the spectra in some cases to contain actual stabilization energies. The different crystal field strength of six nitrogens in nickel(II) amine complexes is further illustrated,- e.g. by 1,3-diaminopropane. The bonding of cyanide in paramagnetic complexes is not very strong and the complexes slowly react to form yellow, diamagnetic nickel(II) and colourless copper(I) cyanides. $\beta, \beta^{\prime}, \beta^{\prime \prime}$-tris(ethylamino)amine does not form a tetrahedral complex with nickel(II), since the water in cis-position of the octahedral complex can be exchanged with ammonia, ethylenediamine or glycinate. The last complex has a very hypsochromic spectrum corresponding to a high stabilization energy. The absorption spectra of nickel(II) complexes demonstrate intermediate coupling and decreased values of the Racah parameters of electrostatic interaction between d-electrons, relative to the gaseous ion.
\end{abstract}

\footnotetext{
The first paper of this series ${ }^{1}$ treated nickel(II) complexes with increasing 1 crystal field strength, corresponding to yellow, green, blue, purple and red colours. The four strongest absorption bands can be interpreted as transitions from the groundstate ${ }^{3} \Gamma_{2}\left(F^{\prime}\right)$ to ${ }^{1} \Gamma_{3}(D),{ }^{3} \Gamma_{5}\left(F^{\prime}\right),{ }^{3} \Gamma_{4}\left(F^{\prime}\right)$ and ${ }^{3} \Gamma_{4}(P)$ in the notation of Bethe ${ }^{2}$. It was shown that the singlet state ${ }^{1} \Gamma_{3}(D)$ is intermixed with ${ }^{3} \Gamma_{5}(F)$ and ${ }^{3} \Gamma_{4}(F)$ by effects of intermediate coupling. In the present paper, nickel(II) is studied in different environments, supplied partly by polydentate ligands. Further, characteristic properties of copper(II), compared to nickel(II) complexes will be discussed ${ }^{1}$.
} 
Empirically, the absorption spectre of mixed complexes have led to the ides of averaged environment. For example, except for very small solvent effects, the six atoms in the first co-ordination sphere of an octahedral complex determine the absorption spectrum. The position of the absorption bands can be predicted mainly from one parameter, expressing the average of the positions of the ligands in the spectrochemical series. Thus, Mead ${ }^{3}$ studied mixed ethylenediamine- and oxalate complexes of chromium (III) and cobalt(III); Tsuchida investigated many complexes of the same two metals, e.g. acido-pentammines. Mathieu ${ }^{5}$ investigated the influence of amino-acids on the two residual places in cis-bis(ethylenediamine)cobalt(III) ions. Linhard and Weigel studied the halogenopentammines and the cis- and trans-tetrammines and pentammines of cobalt(III) with carboxyl groups on the residual places ?. Copper(II) complexes with ethylenediamine and other ligands have been studied by Jonassen et al. ${ }^{8}$, copper(II) bis(acetylacetonate) with different solvents by Belford and cobalt(III) complexes by Basolo, Ballhausen and Bjerrum ${ }^{10}$. In some cases crystal fields of pronounced tetragonal symmetry produce new bends by splitting as in trans-Co $\mathrm{en}_{2} \mathrm{Cl}_{2}+$. In the second and third transition group, Delépine's complexes of rhodium(III) and iridium(III) exhibit similar behaviour 11. Since water is exchanged without change of the co-ordination number, the consecutive uptake of six ammonia molecules to nickel(II), studied by J. Bjermum ${ }^{12}$, or of three ethylenediamine molecules, messured by Ballhausen ${ }^{13}$, can also be cited as examples of mixed complexes with water as one of the ligands.

Table 1 gives the absorption spectra measured here of nickel(II) complexes and Table 3 of copper(II) complexes. Table 2 collects the band maxima of nickel(II) and gives also the results of the first paper ${ }^{1}$.

The following abbreviations will be used for the ligands:

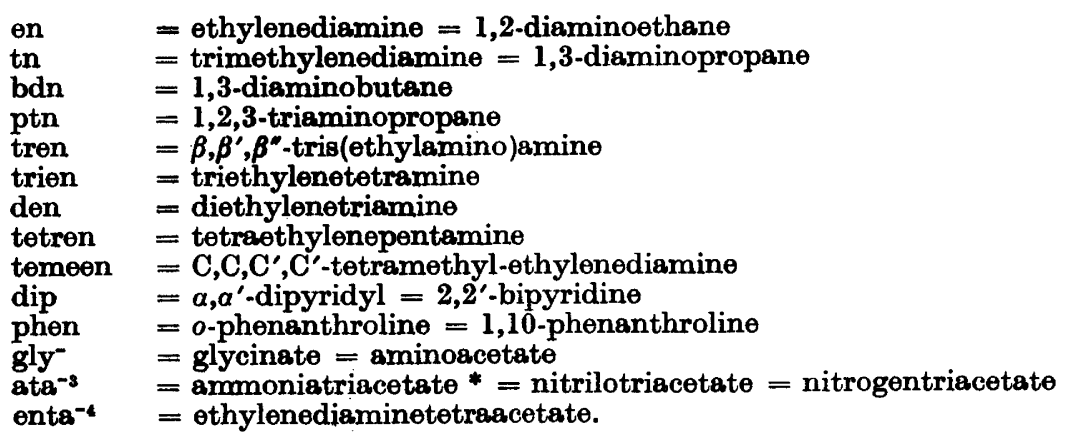

\section{NICKEL(II) ETHYLENEDIAMINETETRAACETATES}

Schwarzenbach ${ }^{14}$ studied the colour reactions of $\mathrm{Ni}$ enta- with $\mathrm{NH}_{3}$, en and $\mathrm{CN}^{-}$. He pointed out that the formation constant of $\mathrm{Ni}^{-1}$ enta $^{--}$is so large that the other ligands do not decompose this complex. While this has a somewhat limited validity in the case of $\mathrm{Ni}^{-12 \mathrm{ta}^{-}}+$en, as discussed below, the ligands must be assumed to exchange with the water present in the first coordination sphere of $\mathrm{Ni}$ enta, $\mathrm{H}_{2} \mathrm{O}^{-}$. The latter complex has a free carboxyl group, which can take up protons ${ }^{15}$ with $\mathrm{p} K=3$, forming Ni enta $\mathrm{H}, \mathrm{H}_{2} \mathrm{O}^{-}$. In Table 1, two forms are given of nickel(II) ethylenediaminetetraacetate, denoted $\alpha$ and $\beta$. The latter form corresponds to the intermediate form which is observed ${ }^{1}$ during the slow formation reactions. However, at low $\mathrm{pH} \sim 3$,

* As proposed by Martell and Calvin in The Chemistry of the Metal Chelate Compounds, New York 1952. Professor.K. A. Jensen has proposed the name "nitrogentriacetate". 
Table 1. Absorption bands of nickel (II) complexes. Wavelength $\lambda_{n}$, wavenumber $\nu_{n}$ and molar extinction coefficient $\varepsilon_{\mathrm{n}}$ of the maxima; $\delta(-)$ and $\delta(+)$ the half-width towards lower and higher wavenumbers, and $\mathbf{P}$ the oscillator strength for each band.

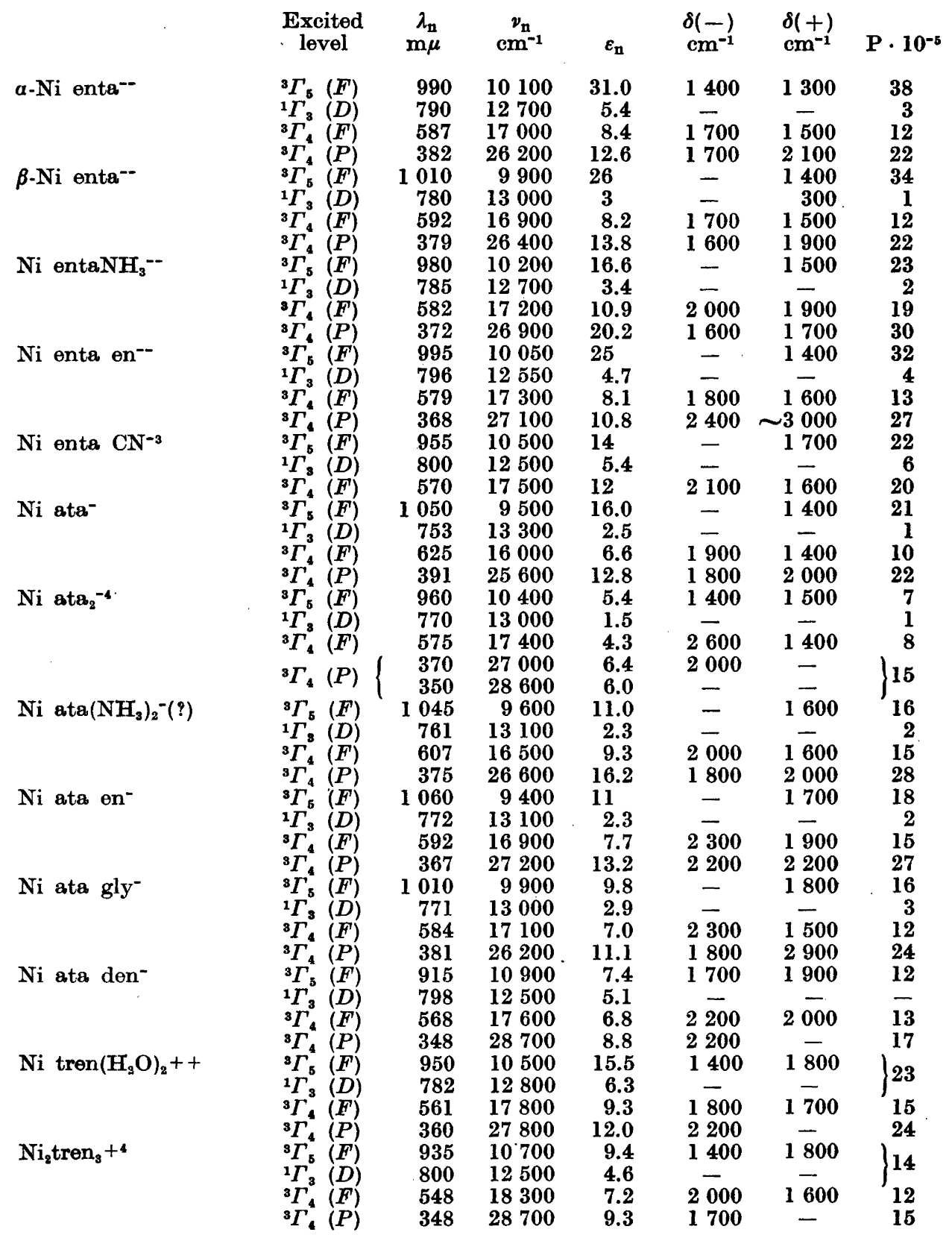

Acta Chem. Scand. 10 (1956) No. 6 


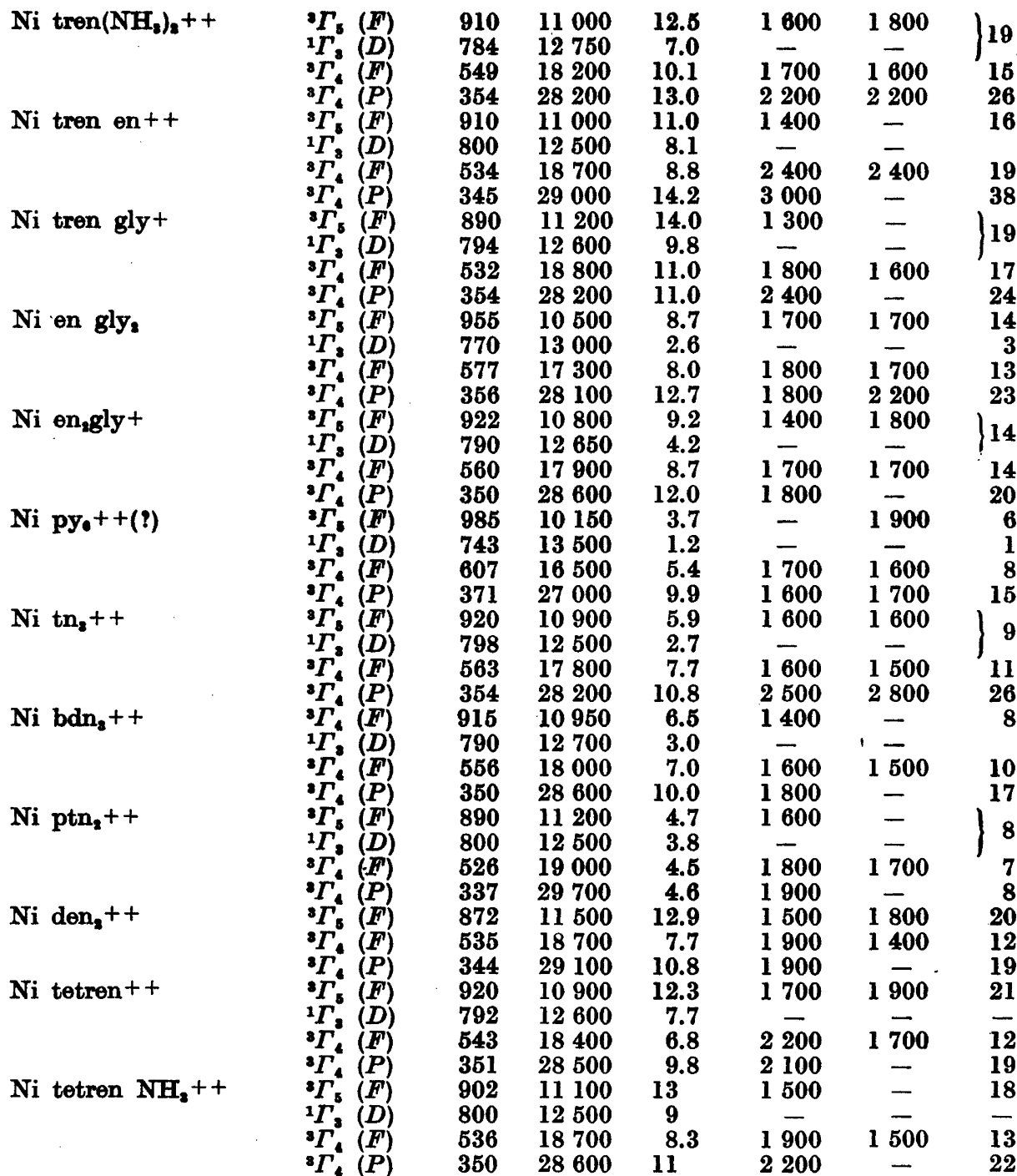

the $\beta$-form is stable and can be formed by addition of acids to the $\alpha$-form. This cannot be due to a partly decomposition to hexaaquo ions, since the fourth band of the $\beta$-form is higher and shifted towards higher wavenumbers than of the $\alpha$-form, while the other three bands show a different behaviour *. Since two isomers are possible ${ }^{1}$ for the complex $\mathrm{Ni}$ enta $\left(\mathrm{H}_{2} \mathrm{O}\right)$, with water in cisor trans-position to one of the nitrogen atoms, $\alpha$ - and $\beta$-may represent two

* Plumb, Martell and Bersworth 58 measured the spectra of some enta ${ }^{-4}$-complexes. The height of the first band indicate the $\beta$-structure of their $\mathrm{Ni}$ enta--. 
different equilibrium mixtures, where the equilibrium is changed by the formation of Ni enta $\mathrm{H}, \mathrm{H}_{2} \mathrm{O}^{-}$. But the change might also be due to a variable number of water molecules in the environment. An anhydrous complex analogous to Co enta-, would be promoted by high $\mathrm{pH}$ and might thus participate in the $\alpha$-form.

It is seen from Table 1 that the enormously high intensity of the first band of $\alpha-\mathrm{Ni}$ enta ${ }^{--}$decreases for the addition compounds of $\mathrm{NH}_{3}$, en and $\mathrm{CN}^{-}$, while the other bands show mainly increasing intensities. The fourth band of Ni enta en ${ }^{-}$is not high, but rather broad. This may be ascribed to tetragonal splitting ${ }^{16}$ or to the presence of more isomers. Although enta ${ }^{-4}$ probably occupies only four co-ordination positions in this complex, the question might be raised as to whether one or two $\mathrm{NH}_{3}$ are bound in the ammonia complex. If ammonia is added to $0.1 \mathrm{M} \mathrm{Ni}$ enta- the $\varepsilon$ values of the fourth band are, respectively:

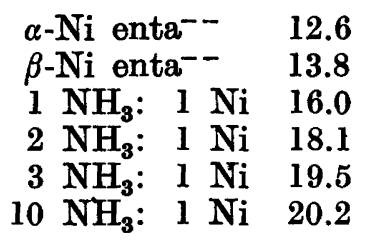

This suggests a formation constant for $\mathrm{Ni}$ enta $\mathrm{NH}_{3}^{--}$of about 20 , leaving $0.05 \mathrm{M}$ free $\mathrm{NH}_{3}$ at its $50 \%$ formation. The small band-width (Table 1) does not suggest the presence of more complexes, but this can of course not be excluded. The intensity demonstrates that the decomposition to enta-free ammonia complexes cannot be advanced. $\log K=1.3$ resembles much the average value ${ }^{12}$ in the nickel(II)-ammonia system, viz. $\log K_{\mathrm{av}}=1.43$, whilst $\log K_{6}=0.01$.

If $1 \mathrm{M}$ potassium cyanide is gradually added to $0.1 \mathrm{M} \mathrm{Ni}$ enta-, a more intense blue-violet colour is observed. The colour becomes distinctly more lilac at the ratio $3 \mathrm{CN}^{-}$: $1 \mathrm{Ni}$. These solutions do not change for several weeks at room temperature. They are, however, slightly decomposed due to local excess concentrations during the preparation as shown by the high absorption in the ultraviolet due to $\sim 1 \% \mathrm{Ni}(\mathrm{CN})_{4}-$. Therefore, the fourth absorption band can only be observed as a shoulder. Solutions in the ratio $5 \mathrm{CN}^{-}: 1 \mathrm{Ni}$ decompose in a few seconds to the yellow colour of diamagnetic nickel(II). The formation constants of the paramagnetic, violet forms are not exceedingly large, as shown by the slow variation of the spectrum with the ratio $\times \mathrm{CN}^{-}$: 1 Ni. A similar behaviour was found by Schwarzenbach ${ }^{14}$ for Co enta $\mathrm{SCN}^{-3}$ which has the formation constant $K=0.7$.

\section{NICKEL(II) NITROGENTRIACETATES}

Schwarzenbach and Biedermann ${ }^{17}$ found two nitrogentriacetate complexes of several metal ions, e.g. Ni ata and $\mathrm{Ni}$ ata $_{2}^{-4}$ with $\log K_{1}=11.26$ (as later determined by Schwarzenbach and Freitag ${ }^{59}$ ) and $\log K_{2}=4.7$. As seen in Table 1, the first band of blue-green $\mathrm{Ni}$ ata ${ }^{-}$is not as high as that of $\mathrm{Ni}$ enta--

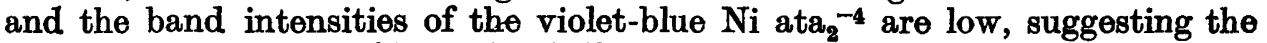
presence of a centre of inversion ${ }^{10,18}$. It is not known whether ata $^{-3}$ functions

Acta Chem. Scand. 10 (1956) No. 6 
as a tri- or tetradentate ligand, but this will not be of great importance to the spectra, since $\mathrm{H}_{2} \mathrm{O}$ and $\mathrm{RCOO}^{-}$are nearly adjacent in the spectrochemical series. In the $\mathrm{Ni}$ ats ${ }_{2}^{-4}$, one would for symmetry reasons expect bonding of one nitrogen and two carboxyl groups from each ligand. The two nitrogen atoms may be in cis- or trans-configuration. The cis-form does not seem very likely, since the intensity relations are different from $\mathrm{Ni}$ enta ${ }^{-2}$ with two cis-nitrogens. The fourth band of $\mathrm{Ni}$ ata $_{2}{ }^{-4}$ has a shoulder on the side of high wavenumbers, and the second band a less pronounced shoulder towards the lower wavenumbers. This may be ascribed to tetragonal effects (of the rare "compressed" type ${ }^{11,16}$ in the trans-complex) or to the presence of different isomers.

The uptake of ammonia and ethylenediamine in $\mathrm{Ni}$ ata- does not lead to very high displacements towards higher wavenumbers (Table 1) whereas glycinate in Ni ata gly has a stronger effect. The first absorption band is particularly difficult to move, and the direction of change is even opposite to that expected for $\mathrm{Ni}$ ata $\mathrm{en}^{-}$. $\mathrm{Ni}_{\text {ata }}$ - decomposes very rapidly upon addition of $\mathrm{CN}^{-}$probably due to more positions for "attack" than in $\mathrm{Ni}$ enta- $\mathrm{Ni}$ ata den- has broad bands with relatively very high wavenumbers.

\section{NICKEL(II) tren-COMPLEXES}

Cox and Webster ${ }^{10}$ investigated the crystal structure of $\mathrm{Ni} \operatorname{tren}(\mathrm{SCN})_{2}$, which could either be a cis-octahedral or a tetrahedral complex. Mr. C. J. Ballhausen and the present author have a year ago measured the spectrum of $\mathrm{Ni}$ tren ${ }^{++}$which is similar to that of $\mathrm{Ni} \mathrm{en}_{2}{ }^{++}$, strongly supporting the cisdiaquo configuration. Mr. S. E. Rasmussen has kindly presented me with a sample of anhydrous $\mathrm{Ni} \operatorname{tren}(\mathrm{SCN})_{2}$ which in $0.03 \mathrm{M}$ aqueous solution has an identical spectrum. In solution, the thiocyanate ions are thus exchanged with water.

Data in Table 1 show that $\mathrm{Ni}$ tren ${ }^{++}$reacts with dilute $\mathrm{NH}_{3}$ and one mole of en with a slight displacement of the bands towards lower wavenumbers, as expected for the exchange of $\mathrm{H}_{2} \mathrm{O}$ by $\mathrm{NH}_{3}$ and en in an octahedral complex. Most surprising is the behaviour of the purplish red $\mathrm{Ni}$ tren gly ${ }^{+}$, which is much more hypsochromic than either $\mathrm{Ni}$ tren ${ }^{++}, \mathrm{Ni} \mathrm{gly}_{3}{ }^{-}$or $\mathrm{Ni}_{2} \mathrm{tren}_{3}{ }^{+4}$. This deviation from the rule of average environment can be ascribed to an actual chelate effect, or to the electrostatic effect of binding one glycinate and thus decreasing the external charge. On the other hand $\mathrm{Ni} \mathrm{en}_{2}$ gly $^{+}$is not so strongly hypsochromic.

With excess tren, $\mathrm{Ni}$ tren ${ }^{++}$forms the complexes $\mathrm{Ni}_{2}$ tren $_{3}{ }^{+4}$ or $\mathrm{Ni}$ tren ${ }_{2}{ }^{++}$ with a crystal field strength similar to that of $\mathrm{Ni} \mathrm{n}_{3}{ }^{++}$. Similar behaviour was found by Jonassen and Douglas ${ }^{20}$ for nickel(II) complexes of triethylenetetramine $=$ trien. The spectra found for $\mathrm{Ni}$ trien ${ }^{++}$and $\mathrm{Ni}_{2}$ trien $_{3}{ }^{++}$have the absorption bands at almost the same wavenumbers as do $\mathrm{Ni} \mathrm{en}_{2}{ }^{++}$and $\mathrm{Ni}$ $\mathrm{en}_{3}{ }^{++}$, respectively. Jonassen and Douglas ${ }^{2 \theta}$ have measured the double band, corresponding to the intermixing ${ }^{1}$ of ${ }^{1} \Gamma_{3}(D)$ and ${ }^{3} \Gamma_{5}(F)$, but did not draw the curves through the points. In the case of $\mathrm{Hg}$ tren $^{++}$, Prue and Schwarzenbach ${ }^{42}$ demonstrated the existence of mixed complexes with chloride and bromide ions on the residual places. Cf. also the observations by Mann ${ }^{66}$ of hexaco-ordinated $\mathrm{Pt}$. trenI $\mathrm{I}_{2}$ and $\mathrm{Pt} \mathrm{ptn}_{2}{ }^{++}$. 


\section{NICKEL(II) COMPLEXES OF ETHYLENEDIAMINE AND GLYCINATES}

Ballhausen ${ }^{13}$ determined the spectra of $\mathrm{Ni}$ en $\left(\mathrm{H}_{2} \mathrm{O}\right)_{4}{ }^{++}$and $\mathrm{Ni}$ en $\mathrm{n}_{2}\left(\mathrm{H}_{2} \mathrm{O}\right)_{2}{ }^{++}$ from the observed spectra of $\mathrm{Ni}^{++}$-en-mixtures treated by the method of $\mathrm{J}$. Bjerrum ${ }^{12}$. However, Ballhausen did not observe the weak singlet transition ${ }^{1}$ to ${ }^{1} \Gamma_{3}(D)$. In mixtures of $1 \mathrm{Ni}: \mathrm{l}$ en, a narrow band can be distinguished at $734 \mathrm{~m} \mu$ with an effective $\varepsilon=2.1$. Since the mixed spectrum of $\mathrm{Ni}^{++}+\mathrm{Ni}$ $\mathrm{en}_{2}{ }^{++}$is approximately a horizontal line in this wavelength range ${ }^{13}$, the measured band occurs at the same place for pure $\mathrm{Ni}$ en ${ }^{++}$as it does for the mixture (18\% each of $\mathrm{Ni}^{++}$and $\mathrm{Ni}$ en $_{2}{ }^{++}$and $64 \% \mathrm{Ni}$ en ${ }^{++}$at $\bar{n}=1$ ).

$\mathrm{Ni}$ en gly $^{+}$was measured (Table l) for comparison with $\mathrm{Ni}$ tren $\mathrm{gly}^{+}$. The spectrum of $\mathrm{Ni}^{-\mathrm{en}_{2}} \mathrm{gly}^{+}$is not changed noticeably with excess of $\mathrm{gly}^{-}$. However, the formation constants with en are so large ${ }^{12}$ relative to glycinate ${ }^{21}$ that no appreciable disproportionation occurs.

Further the spectrum of $\mathrm{Ni}$ en $\mathrm{gly}_{2}$ was determined in solution (Table 1), which for similar reasons does not deviate much from that of the pure complex. The spectra agree well with the interpolation between $\mathrm{Ni} \mathrm{en}_{3}{ }^{++}$and $\mathrm{Ni}^{+} \mathrm{gly}_{3}{ }^{-}$.

\section{NICKEL(II) COMPLEXES OF VARIOUS AMINES}

In the first paper ${ }^{1}$, several nickel(II) complexes were studied with six nitrogen atoms surrounding the central ion, viz. $\mathrm{Ni}\left(\mathrm{NH}_{3}\right)_{6}{ }^{++}, \mathrm{Ni}$ en ${ }_{3}^{++}, \mathrm{Ni}$ $\operatorname{dip}_{3}{ }^{++}$and $\mathrm{Ni}$ phen $_{3}{ }^{++}$. The crystal field strength $\left(E_{1}-E_{2}\right)$ varies from 10800 to $12200 \mathrm{~cm}^{-1}$ in this series. Since the groundstate is stabilized 1.2 $\left(E_{1}-E_{2}\right)$ by the $\gamma_{5}^{6} \gamma_{3}{ }^{2}$-configuration ${ }^{22}$, this represents a considerable range of energy differences, relative to $\left(E_{1}-E_{2}\right)=8500 \mathrm{~cm}^{-1}$ in $\mathrm{Ni}\left(\mathrm{H}_{2} \mathrm{O}\right)_{6}{ }^{++}$. J. Bjerrum and the present author pointed out ${ }^{23}$ that these stabilizations actually can be found in the values of $\Delta G$ for formation of nickel(II) complexes, compared with the similar values of $\mathrm{Ca}^{++}, \mathrm{Mn}^{++}$and $\mathrm{Zn}^{++}$without crystal field stabilization. There has been much discussion ${ }^{24}$ as to whether the large formation constants for complexes with chelates are only due to effects of entropy, leaving $\Delta H$ nearly constant, or if a real "chelate effect" exists also in the bond strength. Since the absorption spectra demonstrate stronger stabilization of ethylenediamine than of ammonia complexes, the chelate effect according to I. Poulsen and J. Bjerrum ${ }^{25}$ must be partly real in the complexes with unfilled d-shells, while it may be due to entropy alone in complexes with closed shells. I. Poulsen and J. Bjerrum ${ }^{25}$ also investigated $\Delta G$ and $\Delta H$ of nickel(II) and copper(II) complexes with $\mathrm{tn}$. Trimethylenediamine was found to be distinctly weaker bound to these metal ions than ethylenediamine. As seen from Tables 1 and 2 the place of th in the spectrochemical series is between $\mathrm{NH}_{3}$ and en, and rather near to $\mathrm{NH}_{3}$. Except for the first absorption band of $\mathrm{Ni} \mathrm{tn}_{3}{ }^{++}$, the bands are higher than that of $\mathrm{Ni} \mathrm{en}_{3}{ }^{++}$, as often found by increasing size of the organic ligand ${ }^{18}$.

Similar behaviour is found in $\mathrm{Ni} \mathrm{bdn}_{3}{ }^{++}$, as by C-methylsubstituted ethylenediamine complexes studied by $\mathrm{F}$. Basolo. The position of bdn in the spectrochemical series is between tn (of which it is the methyl substitute) and en. 
Table 2. The four strong absorption bands in nickel(II) complexces, classified according to the number of nitrogen atoms in the first co-ordination sphere. Wavenumbers of maxima in $\mathrm{cm}^{-1}$.

0 nitrogen:

$\mathrm{Ni}\left(\mathrm{H}_{2} \mathrm{O}\right)_{6}++$

1 nitrogen:

$\mathrm{Ni} \operatorname{ata}\left(\mathrm{H}_{8} \mathrm{O}\right)_{2}^{-}$

2 nitrogens:

a- $\mathrm{Ni}$ enta $\left(\mathrm{H}_{2} \mathrm{O}\right)^{+-}$

$\beta$-Ni enta $\left(\mathrm{H}_{2} \mathrm{O}\right)^{--}$

Ni ata gly--

Ni ata -6

3 nitrogens:

$\mathrm{Ni} \operatorname{ata}\left(\mathrm{NH}_{\mathbf{8}}\right)_{\mathbf{2}}^{-}{ }^{-1}$ ?

Ni ata en-

$\mathrm{Ni}$ enta( $\left(\mathrm{NH}_{\mathbf{8}}\right)^{-}$

Ni gly:-

$\mathrm{Ni}$ enta (CN)

4 nitrogens:

$\mathrm{Ni}\left(\mathrm{NH}_{3}\right)_{4}\left(\mathrm{H}_{2} \mathrm{O}\right)_{2}++$

Ni enta en ${ }^{-}$

$\mathrm{Ni}$ en $\mathrm{gly}_{2}$

$\Gamma_{5}\left(F^{\prime}\right) \quad \Gamma_{3}(D)$

${ }^{3} \Gamma_{.}\left(F^{\prime}\right)$

${ }^{3} \Gamma_{4}(P)$

8500

(13 500)

(15 400)

25300

9500

13300

16000

25600

9800

13600

10100

12700

9900

12800

15800

17000

16900

17100

10400

13000

17400

26800

26200

26400

26200

9600

9400

13100

13100

16500

27000

10200

12700

13100

10100

12500

16900

26600

17200

16600

17600

10050

$\overline{12550}$

10500

13500

12800

16700

10500

$\mathrm{Ni}$ tren $\left(\mathrm{H}_{3} \mathrm{O}\right)_{\mathbf{2}}++$

Ni ata den ${ }^{-}$.

10500

10900

$1 \overline{2500}$

17300

17300

17800

17900

5 nitrogens:

$\mathrm{Ni}\left(\mathrm{NH}_{8}\right)_{6}\left(\mathrm{H}_{2} \mathrm{O}\right)++$

$\mathrm{Ni}$ en $\mathrm{gly}^{+}$

$\mathrm{Ni}$ tetren++

Ni tren gly+

6 nitrogens:

$\mathrm{Ni} \mathrm{py}^{++}+$(?)

$\mathrm{Ni}\left(\mathrm{NH}_{2}\right)_{6}++$

$\mathrm{Ni} \mathrm{tn}_{\mathrm{a}}++$

$\mathrm{Ni}$ bdn $_{3}++$

Ni en $_{8}++$

$\mathrm{Ni} \operatorname{tren}\left(\mathrm{NH}_{\mathbf{3}}\right)_{\mathbf{2}}++$

$\mathrm{Ni}_{3}$ tren $_{3}+4$

$\mathrm{Ni}$ tren ent+

$\mathrm{Ni}$ tetren $\mathrm{NH}_{3}++$

Ni den $_{2}++$

Ni $\operatorname{ptn}_{2}++$

Ni $\operatorname{dip}_{3}++$

Ni phen $_{3}++$

$1 \overline{10} 800$

$-$

17600

27200

26900

27600

10900

12650

12600

17250

17900

18400

-

11200

12600

18800

27100

28100

27800

28100

28700

10150

13500

13150

16500

10750

12500

17500

17800

18000

10950

12700

12400

18350

18200

11000

12750

12500

12500

11000

11100

12500

11500

11200

(11 500)

$12 \overline{500}$

(12 650)

(11 550)

(12 700)

18300

18700

18700

18700

19000

19200

19300

$28 \overline{600}$

28500

28200

27000

28200

28200

28600

29000

28200

28700

29000

28600

29100

29700

Prue and Schwarzenbach ${ }^{26}$ have studied the complex formation with 1,2,3-triaminopropane. It is found here that at least two complexes are formed in solutions with up to three moles ptn per nickel ion. The purple complex finally formed (presumably $\mathrm{Ni} \mathrm{ptn}_{2}{ }^{++}$) has about $1 \%$ higher value of $\left(E_{1}-E_{2}\right)$ than $\mathrm{Ni}$ en $_{3}{ }^{++}$, but has lower band maxima. The upper limit of $\left(E_{1}-E_{2}\right)$ for aliphatic amines does not seem to be more than $1 \%$ higher than that of en, as exemplified by tren, trien and ptn, while larger alkyl radicals and larger chelate rings, as in tn and to a lesser degree in bdn have an decreasing influence on bonding strength. 
Another aliphatic amine with a high crystal field strength is $\mathrm{C}, \mathrm{C}, \mathrm{C}^{\prime}, \mathrm{C}^{\prime}$ tetramethyl-ethylenediamine of which Basolo, Chen and Murmann report ${ }^{27}$ diamagnetic, planar yellow ions $\mathrm{Ni}$ temeen ${ }_{2}{ }^{++}$(with only one absorption maximum ${ }^{27}$ at $23000 \mathrm{~cm}^{-1}$, while the reflection spectrum of the salmon-pink ${ }^{16}$ solid $\left[\mathrm{Ni}\right.$ en $\left.{ }_{2}\right][\mathrm{AgBrI}]_{2}$ shows a band at $20800 \mathrm{~cm}^{-1}$ ). Basolo and the present author observed that solid $\left[\mathrm{Ni}\right.$ temeen ${ }_{2}$ ] $\mathrm{Cl}_{2}$ reacts with concentrated aqueous ammonia to a violet solution *. It was obvious to suppose the existence of a paramagnetic ion $\mathrm{Ni}$ temeen ${ }_{2}\left(\mathrm{NH}_{3}\right)_{2}{ }^{++}$. However, the solution shows bands at nearly the same place as $\mathrm{Ni}\left(\mathrm{NH}_{3}\right)_{6}{ }^{++}$, and a solution, $0.05 \mathrm{M} \mathrm{Ni}^{++}, 6 \mathrm{M}$ $\mathrm{NH}_{3}, 0.12 \mathrm{M}$ temeen, which contains less than $2 \%$ of the yellow form, is decomposed by addition of 50 volume $\% 0.4 \mathrm{M}$ temeen to a mixture of about $60 \% \mathrm{Ni}^{2}$ temeen ${ }_{2}{ }^{++}$and $40 \%$ of the violet form. It is not a reasonable behaviour for a mixed ammonia complex, but is rather caused by the sudden break-down of the chelate complex at increasing ammonia concentration, as discussed below. Basolo, Chen and Murmann ${ }^{27}$ found that $\mathrm{Ni}$ temeen $_{3}{ }^{++}$ cannot be formed, due to steric hindrance; and $\mathrm{Ni}$ temeen $\mathrm{Cl}_{2}$ has the same absorption spectrum in water and absolute ethanol, showing no tendency of solvation or association of chloride ions in the first co-ordination sphere. Neither has it been possible to identify a purple cis-Ni temeen ${ }_{2} \mathrm{en}^{++}$in mixed solutions.

Although the heterocyclic diamines as $\alpha, \alpha^{\prime}$-dipyridyl and $o$-phenanthroline have even larger crystal field strengths ${ }^{1}$ than ethylenediamine, the heterocyclic monamine pyridine has a smaller crystal field strength than ammonia. It is not easy to identify the hypothetical Ni $\mathrm{py}_{6}{ }^{++}$in solution. The solutions of nickel(II) nitrate in pyridine with a small water content may still contain nitrato complexes ${ }^{28}$, which perhaps also were important in the system $n$ butylamine-water-copper(II) nitrate, studied by Bjerrum and Lamm ${ }^{23}$. Robust complexes of cobalt(III) and rhodium(III) are only known with at most four molecules of pyridine. Nevertheless, the results in Table 1 and 2 demonstrate a low crystal field strength of pyridine, compared to other amines agreeing well with the observed weak tendency to complex formation ${ }^{\mathbf{5 1}}$.

Table 1 gives also the spectra of $\mathrm{Ni} \mathrm{den}_{2}{ }^{++}, \mathrm{Ni}$ tetren ${ }^{++}$, and $\mathrm{Ni}$ tetren $\mathrm{NH}_{3}{ }^{++}$, demonstrating the regular behaviour of nickel(II), compared to copper(II), of which Table 3 gives $\mathrm{Cu}$ den ${ }^{++}, \mathrm{Cu}$ den $\mathrm{NH}_{3}{ }^{++}, \mathrm{Cu} \mathrm{den}{ }_{2}{ }^{++}$, and $\mathrm{Cu}$ tetren ${ }^{++}$. The latter series of complexes resembles much the spectra of $\mathrm{Cu}\left(\mathrm{NH}_{3}\right)_{n}\left(\mathrm{H}_{2} \mathrm{O}\right)_{6-n}^{++}$with $\mathrm{n}=3,4,6$, and 5, respectively, exhibiting pentammine effect in the two last cases ${ }^{32}$. Haendler ${ }^{67}$ measured the absorption spectra of $\mathrm{Cu}^{++}$and $\mathrm{Ni}^{++}$with 1 and 2 moles of den. While $K_{1} / K_{2}$ is so large in the first case that $\mathrm{Cu}$ den ${ }^{++}$disproportionates only to the extent $10^{-5.4}, 5 \%$ each of $\mathrm{Ni}^{++}$and $\mathrm{Ni} \operatorname{den}_{2}{ }^{++}$occur for $\mathrm{n}=1$. The complex formation with the "guirlande" chain amines den, trien, tetren with $\mathrm{H}_{2} \mathrm{O}$ and $\mathrm{NH}_{3}$ on the residual places will be discussed later.

* However, Basolo isolated a violet solid from the action of liquid ammonia. Since this solid returns to the original yellow complex upon standing in the air, Basolo assumes the solid to be the mixed complex $\left[\mathrm{Ni}\right.$ temeen,$\left.\left(\mathrm{NH}_{3}\right)_{2}\right] \mathrm{Cl}_{2}$. (Private communication). 
Table 3. Absorption bands of copper (II) complexes. Notation as in Table 1.

\begin{tabular}{|c|c|c|c|c|c|c|}
\hline & $\underset{\mathbf{m} \mu}{\lambda_{\mathbf{n}}}$ & $\begin{array}{c}v_{n} \\
\mathbf{c m}^{-1}\end{array}$ & $\varepsilon_{\mathbf{n}}$ & $\begin{array}{l}\delta(-1) \\
\mathrm{cm}^{-1}\end{array}$ & $\begin{array}{l}\delta(+) \\
\mathrm{cm}^{-1}\end{array}$ & $P \cdot 10^{-5}$ \\
\hline $\begin{array}{l}\text { Cu enta-- } \\
\text { Cu enta NH.-- }\end{array}$ & 734 & 13600 & $\begin{array}{l}91 \\
38\end{array}$ & 2000 & 2200 & $\begin{array}{r}185 \\
75\end{array}$ \\
\hline Cu ata- & $\begin{array}{l}882 \\
775\end{array}$ & $\begin{array}{l}11400 \\
12900\end{array}$ & $\begin{array}{l}60 \\
60 \\
54\end{array}$ & 2400 & $2 \frac{-}{600}$ & 170 \\
\hline $\mathrm{Cu} \mathrm{ata}_{2}^{-4}$ & 658 & 15200 & 37 & 2700 & 2400 & 90 \\
\hline $\mathrm{Cu}$ tren ++ & 860 & 11600 & 117 & 2600 & 3300 & 320 \\
\hline $\mathrm{Cu}$ tren $\left(\mathrm{NH}_{3}\right)_{2}++$ & 785 & 12700 & 134 & 2500 & $3 \mathbf{3 0 0}$ & 360 \\
\hline Cu dent+ & 611 & 16300 & 74 & 2300 & 2600 & 170 \\
\hline $\mathrm{Cu}$ den $\mathrm{NH}_{3}++$ & 576 & 17400 & 84 & 2600 & 2600 & 200 \\
\hline $\mathrm{Cu}$ den $_{2}++$ & $\sim \mathbf{8 5 0}$ & $\begin{array}{l}11800 \\
15900\end{array}$ & $\sim 70$ & 1800 & $\frac{-}{600}$ & 310 \\
\hline Cu tetren ++ & $\begin{array}{r}\mathbf{8 4 0} \\
\mathbf{6 4 3}\end{array}$ & 11900 & $\sim 100$ & 1700 & $\overline{400}$ & 520 \\
\hline 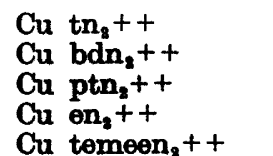 & $\begin{array}{l}\mathbf{5 6 8} \\
\mathbf{5 6 6} \\
\mathbf{5 5 9} \\
\mathbf{5 4 9} \\
\mathbf{5 4 7}\end{array}$ & $\begin{array}{l}17600 \\
17700 \\
17900 \\
18200 \\
18300\end{array}$ & $\begin{array}{r}111 \\
125 \\
66 \\
63 \\
120\end{array}$ & $\begin{array}{ll}2 & 700 \\
2 & 500 \\
2 & 300 \\
2 & 400 \\
2 & 700\end{array}$ & $\begin{array}{ll}2 & 300 \\
2 & 300 \\
2 & 200 \\
2 & 400 \\
2 & 500\end{array}$ & $\begin{array}{l}250 \\
280 \\
140 \\
140 \\
290\end{array}$ \\
\hline
\end{tabular}

\section{COPPER(II) ETHYLENEDIAMINETETRAACETATES}

It was shown above that the absorption spectra of paramagnetic nickel(II) complexes can be described roughly by only one parameter, which may be identified with the energy difference $\left(E_{1}-E_{2}\right)$ between $\gamma_{3}$-and $\gamma_{5}$-electrons in a regularly octahedral complex ${ }^{13,16,30,31}$. In copper(II) complexes, one further parameter is necessary to describe the relative tetragonality ${ }^{2}$ varying from a regular octahedron to square planar complexes with decreasingly weaker ligands on the perpendicular axis. Empirically, the ratio $v_{\mathrm{Cu}} / \nu_{\mathrm{Ni}}$ between the principal band of the copper(II) complex and the first band of the corresponding nickel(II) complex is proposed ${ }^{1}$. This ratio is roughly 1 in copper (II) complexes with cubic symmetry, increasing to about 1.8 in the most extremely tetragonal cases.

J. Bjerrum, Ballhausen and the author ${ }^{32}$ discussed previously the ligands ammonia and ethylenediamine, which form the distinctly tetragonal planar complexes $\mathrm{Cu}\left(\mathrm{NH}_{3}\right)_{4}{ }^{++}$and $\mathrm{Cu}$ en $_{2}{ }^{++}$with two weakly bound water molecules, resulting in $\nu_{\mathrm{Cu}} / \nu_{\mathrm{Ni}}=1.7$. If stronger bound ligands such as ammonia, replace water on the $z$-axis, a pentammine effect is observed to decrease the value of this ratio. Recently Linford ${ }^{9}$ studied the solvates of copper(II) bis(acetylacetonate) and similar planar complexes with chloroform, acetone, dioxan, alcohols, pyridine and piperidine solvates, arranged according to increasing $z$-axis contribution. Most of the results obtained are readily explained except for the absorption band of $\mathrm{Cu} \mathrm{en}_{2}{ }^{++}$which is shifted $800 \mathrm{~cm}^{-1}$ in the wrong direction by solvation with ethanol ${ }^{33}$. This effect is much larger than the solvation effects of the second co-ordination sphere, studied by J. Bjerrum, Adamson, and Bostrup ${ }^{34}$.

A series of copper(II) complexes with much lower values of $\nu_{\mathrm{Cu}} / \nu_{\mathrm{Ni}}$ have been investigated ${ }^{1}$. The behaviour of amines as ligands is rather capricious, 
some form "cubic" and some "tetragonal" complexes without conspicuous regularities. The polydentate amino-acids, however, form only weakly tetragonal copper(II) complexes whenever, of steric reasons, the carboxyl groups cannot be bound in the plane of four strongly bound atoms. In the case 1 of $\mathrm{Cu}$ enta $\left(\mathrm{H}_{2} \mathrm{O}\right)^{--}$we have $\nu_{\mathrm{Cu}} / \nu_{\mathrm{Ni}}=1.36$.

Bonnett and Schmidt ${ }^{35}$ found that the less coloured $\mathrm{Cu}$ enta $(\mathrm{OH})^{-3}$ is formed with $\mathrm{p} K=11.35$ in $1 \mathrm{M} \mathrm{Na}_{2} \mathrm{SO}_{4}$ and with higher $\mathrm{p} K$ at lower ionic strength. Schwarzenbach and Heller ${ }^{36}$ found $\mathrm{p} K=7.39$ for the acidity of $\mathrm{Cr}$ enta $\left(\mathrm{H}_{2} \mathrm{O}\right)^{-}$and 7.49 for the first proton of $\mathrm{Fe}$ enta $\left(\mathrm{H}_{2} \mathrm{O}\right)^{-}$. It is known from $\mathrm{pK}$ of $\mathrm{Cu}\left(\mathrm{H}_{2} \mathrm{O}\right)_{6}{ }^{++}$and from the formation ${ }^{32}$ of $\mathrm{Cu}\left(\mathrm{NH}_{3}\right)_{3} \mathrm{OH}^{+}$that copper(II) complexes generally are more acidic than those of nickel(II) and zinc(II). Even though the external charge and the oxidizing power (the intermixing of electron transfer states stabilizes perhaps the groundstate of the hydroxo complexes) make an important contribution to the acidity, there is, inter alia, an evident effect of deviation from cubic symmetry for metal ions with unfilled $d$-shells ${ }^{22}$. This is especially evident for the tetragonal $d^{4}$ - and $d^{9}$ systems.

Data in Table 3 show that the band of $\mathrm{Cu}_{\text {entaNH}}{ }^{--}$has much lower intensity than that of $\mathrm{Cu}$ enta $\mathrm{H}_{2} \mathrm{O}^{--}$. This cannot be ascribed to the formation of $\mathrm{Cu}$ enta $\mathrm{OH}^{-}-$in aqueous ammonia, since addition of a large amount of $\mathrm{NH}_{4} \mathrm{NO}_{3}$ has no effect on the spectrum. The maximum in $\mathrm{Cu}_{\text {entaNH}}{ }^{--}$is only shifted $2 \%$ towards higher wavenumbers, celative to $\mathrm{Cu}_{\text {entaH }} \mathrm{O}^{-}-$. Thus, the ammonia molecule must be placed on the axis, perpendicular to the plane containing the two cis-nitrogen atoms of enta ${ }^{-4}$.

Upon addition of KCN to $0.02 \mathrm{M} \mathrm{Cu} \mathrm{enta}^{-3}$, the maximum at $734 \mathrm{~m} \mu$ is displaced to $719 \mathrm{~m} \mu$ with $1 \mathrm{CN}^{-}: 1 \mathrm{Cu}$ and to $706 \mathrm{~m} \mu$ with $3 \mathrm{CN}: 1 \mathrm{Cu}$. The corresponding violet colours can be changed even further towards brownish purple. Such solutions are very unstable (the lowest maximum measured is $695 \mathrm{~m} \mu$ ) and change in a minute to colourless copper(I) cyanide complexes. It is interesting to note that a high electron transfer spectrum in the violet is present in the intermediate copper(II) complex. Representative values of the effective $\varepsilon$ are 16 at $400 \mathrm{~m} \mu, 75$ at $375 \mathrm{~m} \mu$ and 280 at $350 \mathrm{~m} \mu$, while the decomposed solution has only $\varepsilon=9$ at $350 \mathrm{~m} \mu$ and $\varepsilon=20$ at $325 \mathrm{~m} \mu$. Also $\mathrm{Cu}$ enta $^{-}$has an electron transfer spectrum ${ }^{1}$ with $\varepsilon=46$ at $350 \mathrm{~m} \mu$, and similar values are found for $\mathrm{Cu}$ enta $\mathrm{NH}_{3}^{--}$.

Thus, the intrinsic tendency of a redox process in $\mathrm{Cu}$ enta $(\mathrm{CN})^{-3}$ is depicted by the electron transfer spectrum, as is also the case of $\mathrm{CuCl}_{4}^{--}$and $\mathrm{CuBr}_{4}^{--}$. Duke and Courtney ${ }^{37}$ demonstrated the strong colour produced in copper(II) solutions in ammonia water by $\mathrm{CN}^{-}$, which contained rather stable complexes of the type $\mathrm{Cu}\left(\mathrm{NH}_{3}\right)_{3} \mathrm{CN}^{+}$. Analogously, $\mathrm{Cu}$ en ${ }^{++}$forms purple and reddish intermediate complexes with $\mathrm{CN}^{-}$, probably corresponding to high values of the tetragonality. The position of $\mathrm{CN}^{-}$is at the extreme end of the spectrochemical series. For example the first band of tris(ethylenediamine) complexes of cobalt(III), rhodium(III) and iridium(III) ${ }^{38}$ has 1.30 times as large a wavenumber as in the corresponding hexaaquo ions. The similar ratio is 1.96 for $\mathrm{Co}(\mathrm{CN})_{6}^{---}$.

Pfeiffer and Schmitz ${ }^{39}$ maintain the existence of enta-complexes with two metal ions in the solid compound $\mathrm{Ca} \mathrm{Cu}$ enta, $3.5 \mathrm{H}_{9} \mathrm{O}$. Although such complexes would be very 


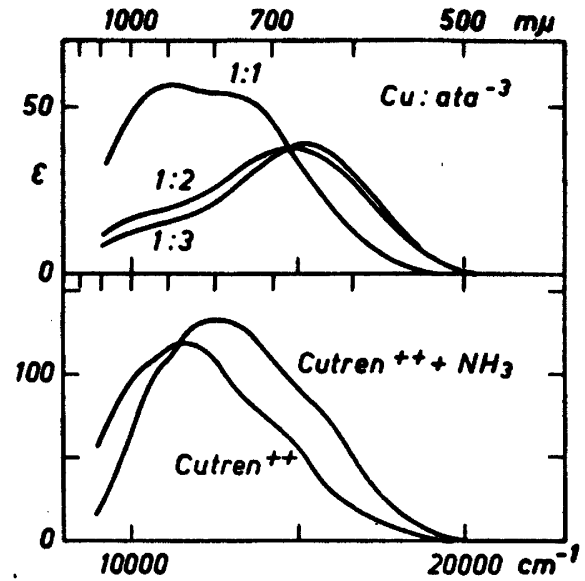

Figure 1. Upper part: Absorption spectra, demonstrating the consecutive formation of $\mathrm{Cu}$ ata and $\mathrm{Cu}$ ata. $^{-4}$. The solutions measured were:

$$
\begin{aligned}
& 0.04 M C u++, 0.04 M a t a^{-s} \\
& 0.04 M \mathrm{Cu}++, 0.08 M \text { ata }^{-\mathrm{s}} \\
& 0.04 M \mathrm{Cu}^{++}+, 0.12 M \text { ata }^{-3}
\end{aligned}
$$

Lower part: Absorption spectra of the two complexes $\mathrm{Cu}$ tren $\left(\mathrm{H}_{2} \mathrm{O}\right)_{2}++$ and $\mathrm{Cu}$ tren $\left(\mathrm{NH}_{3}\right)_{2}++$ (or perhaps $\mathrm{Cu}$ tren $\left(\mathrm{NH}_{3}\right)\left(\mathrm{H}_{2} \mathrm{O}\right)++$ ) from solutions:

$0.01 M C u++, 0.01 M$ tren

$0.01 M \mathrm{Cu}+\mathrm{C}^{+}, 0.01 \mathrm{M}$ tren. $1 \mathrm{MNH_{3 }}$

interesting it would not appear that there is any good evidence for their existence. Pfeiffer and Schmitz ${ }^{30}$ found that $\mathrm{Cu}(\mathrm{OH})_{2}$ is precipitated with $\mathrm{NaOH}$ from $\mathrm{CaCu}$ enta, while $\mathrm{Na}_{2} \mathrm{Cu}$ ente is not decomposed. But this may be a consequence of the presence of calcium ions, removing enta-4 from the equilibria by formation of Ca ente-- with log $K=10.59$, while $\mathrm{Cu}$ enta-- has $\log K=18.4$. Mixtures of $\mathrm{Ni}$ enta-- and $\mathrm{Ni}^{+}+$do not react, according to the spectra, and in alkaline solution, $\mathrm{Ni}(\mathrm{OH})_{2}$ is precipitated. The second formation constant of $\mathrm{Ca}^{\mathrm{enta}}{ }_{8}{ }^{-6}$ is ${ }^{61}$ less than 20 , but the investigation is rendered difficult by the relatively low value of $\mathrm{p} K=11.39$ for formation of $\mathrm{Ca}(\mathrm{OH}) \mathrm{enta}^{-3}$. The intention of Pfeiffer and Schmitz ${ }^{80}$ to prepare isomeric enta-salts, differing only in the free metel ion, is more apt to occur with robust species, e.g. $\left[\mathrm{Cr}\left(\mathrm{H}_{2} \mathrm{O}\right)_{6}\right]_{2}[\mathrm{Ni} \text { enta }]_{3}$ and $\left[\mathrm{Ni}\left(\mathrm{H}_{2} \mathrm{O}\right)_{6}\right][\mathrm{Cr} \text { onta }]_{2}$.

\section{COPPER(II) NITROGENTRIACETATES}

The robin-egg's blue Culata- reacts with an excess of ata- to form darker blue complexes. It is seen from Fig. 1 that the formation of $\mathrm{Cu} \mathrm{ata}_{2}{ }^{-4}$ is not totally complete at the ratio $2 \mathrm{ata}^{-3}: 1 \mathrm{Cu}^{+2}$ but the spectrum is a linear combination of that of $\mathrm{Cu}_{\mathrm{ata}}^{-}$with the new complex.

The intensity of $\mathrm{Cu} \mathrm{ata}_{2}^{-4}$ is much lower than of $\mathrm{Cu}_{\mathrm{ata}}-$, analogous to the nickel(II) complexes. Since $\nu_{\mathrm{Cu}} / \nu_{\mathrm{NI}}$ goes from 1.25 for $\mathrm{Cu}^{-}$ata ${ }^{-}$to 1.45 for $\mathrm{Cu}$ ata $_{2}{ }^{-4}$, the two nitrogens in the latter complex determine the tetragonal plan. The development has the opposite direction ${ }^{1}$ in $\mathrm{Cu} \mathrm{gly}_{2}$ with $v_{\mathrm{Cu}} / v_{\mathrm{Ni}}=1.60$, which decreases in $\mathrm{Cu}_{\text {gly }_{3}}{ }^{-}$. The complex formation necessitates in the latter case relatively large free concentrations of the ligand. 
$\mathrm{Cu}$ ata- has two absorption bands (Table 3) with a distance of $1500 \mathrm{~cm}^{-1}$ between the maxima, while $\mathrm{Cu}_{\mathrm{ata}_{2}}^{-4}$ has only an extreme large half-width towards the infra-red. The former phenomenon resembles Cuphen ${ }_{2}\left(\mathrm{H}_{2} \mathrm{O}\right)_{2}{ }^{++}$ and $\mathrm{Cudip}_{2}\left(\mathrm{H}_{2} \mathrm{O}\right)_{2}{ }^{++}$, both of which are presumed to have cis-configuration 1. R. Linn and Geneva Belford ${ }^{9}$ assume that the broad bands of copper (II) complexes can be resolved into three Gaussian curves ${ }^{40}$ with three different half-widths, but with $\delta(-)=\delta(+)$ for each band ${ }^{40}$. While the existence of three bands may be theoretically justified ${ }^{9}$, the determination of their positions is certainly near to the limits of experimental uncertainty. However, at least two bands are constituents of most of the spectra of copper(II) complexes ${ }^{1,32}$, and three are observed in Fig. 1 of $\mathrm{Cu}$ tren ${ }^{++}$.

\section{COPPER(II) tren-COMPLEXES}

$\mathrm{Cu}$ tren ${ }^{++}$is sea-blue with the same tint as the hexaaquo ion and the high band is displaced to $860 \mathrm{~m} \mu$, compared to $\mathrm{Cu}\left(\mathrm{H}_{2} \mathrm{O}\right)_{6}{ }^{++}$at $790 \mathrm{~m} \mu$. Hence the crystal field is strong in $\mathrm{Ni}$ tren $\left(\mathrm{H}_{2} \mathrm{O}\right)_{2}{ }^{++}, \nu_{\mathrm{Cu}} / \nu_{\mathrm{Ni}}$ is only $=1.08$, the lowest value found in any copper(II) complex. Thus, a cis-diaquo configuration for $\mathrm{Cu}$ $\operatorname{tren}\left(\mathrm{H}_{2} \mathrm{O}\right)_{2}{ }^{++}$can be proposed. In aqueous ammonia a flat maximum is obtained at $785 \mathrm{~m} \mu$. This increases the ratio $\nu_{\mathrm{Cu}} / \nu_{\mathrm{Ni}}$ only slightly to 1.11 .

Thus, the tendency of forming cubic copper(II) complexes is not restricted to heterocyclic diamines, but can also be found in aliphatic amines with steric resistance against formation of planar complexes. However, in the discussion of copper(II) complexes of polydentate ligands a special precaution must be taken: Contrary to most calculational assumptions ${ }^{9,16}$, the six atoms in an octahedral complex are not bound to the axes of a Cartesian co-ordinate system, but instead may have a triclinic symmetry. Geometrically a ciscomplex $\mathrm{MA}_{4} \mathrm{~B}_{2}$ with loosely bound $\mathrm{B}$ can smoothly transform to a tetrahedral complex MA, first of non-regular and later of regular symmetry. During this process, the cubic contribution ${ }^{16}$ will change in sign, and the energies of the five d-orbitals, if calculated from the electrostatic model ${ }^{41}$ will cross in a very complicated way. The most stable configuration is obtained when the average energy of the d-electrons is relatively low and the interaction energies of the ligands low, while the highest d-orbital has a relatively high energy. The latter orbital contains only one electron in $\mathrm{Cu}^{++}$. A further complication arises, because the regularly tetrahedral symmetry of copper(II) is unstable, due to the Jahn-Teller effect ${ }^{22}$. Actually, bonding of tren to $\mathrm{Cu}^{++}$is rather strong: Prue and Schwarzenbach ${ }^{42}$ determined log $K=14.65$ for $\mathrm{Zn}$ tren ${ }^{++}$, 18.8 for $\mathrm{Cu}$ tren ${ }^{++}$and $\mathbf{1 4 . 8}$ for $\mathrm{Ni}$ tren ${ }^{++}$. Contrary to this behaviour, the heterocyclic diamines have their formation constants in the order ${ }^{23} \mathrm{Ni}>\mathrm{Cu}>$ $\mathrm{Zn}$. However, the profound analogy (Fig. 1) between the spectra with two shoulders at nearly the same place strongly supports the cis-configuration of mainly octahedral $\mathrm{Cu}$ tren $\left(\mathrm{H}_{2} \mathrm{O}\right)_{2}{ }^{++}$and $\mathrm{Cu} \operatorname{tren}\left(\mathrm{NH}_{3}\right)_{2}{ }^{++}$(or $\mathrm{Cu} \operatorname{tren}\left(\mathrm{NH}_{3}\right)$ $\left.\left(\mathrm{H}_{2} \mathrm{O}\right)^{++}\right)$. 


\section{COPPER(II) COMPLEXES WITH ALIPHATIC DIAMINES}

I. Poulsen and J. Bjerrum ${ }^{25}$ found the formation heats for copper(II) amine complexes for the four first co-ordination places the series $\mathrm{NH}_{3}<\mathrm{tn}$ <en. As seen from Table 3, $v_{\mathrm{n}}$ of $\mathrm{Cu} \mathrm{tn}_{2}{ }^{++}$occurs between that of $\mathrm{Cu}\left(\mathrm{NH}_{3}\right)_{4}{ }^{++}$ and $\mathrm{Cu} e \mathrm{n}_{2}{ }^{++}$and $\nu_{\mathrm{Cu}} / v_{\mathrm{N} 1}$ is therefore 1 1.7. The stabilization energy is probably also roughly proportional to the wavenumber of the principal band in tetragonal complexes.

The highest wavenumber observed yet in a copper(II) complex occurs in

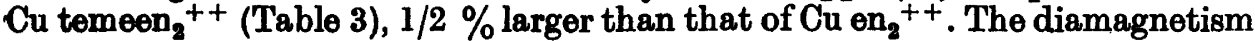
of $\mathrm{Ni}$ temeen ${ }_{2}{ }^{++}$corresponds to an even higher tendency of tetragonality ${ }^{27}$ with the highly destabilized orbital $\gamma_{t 3}$ which is empty ${ }^{16}$.

The tridentate ptn does not utilize the possibility of forming a nearly cubic, hexa-coordinated copper(II) complex such as dip and phen. On the other hand $\mathrm{Cu} \mathrm{ptn}_{2}{ }^{++}$is dark violet with $v_{\mathrm{Cu}} / v_{\mathrm{Ni}}=1.6$ and must be assumed to bind only four nitrogen atoms, as already proposed by Mann and Pope ${ }^{65}$. It would be interesting to know, if the residual amine group has affinity to silver ions, forming perhaps the bi-nuclear complex $\mathrm{Cu} \mathrm{ptn}_{2} \mathrm{Ag}^{+3}$ with linear environment of the silver ${ }^{12,60}$.

While the tridentate amines ptn and den (of which the latter has one secondary amine group) form similar nickel(II) complexes, is $\mathrm{Cu} \mathrm{den}_{2}{ }^{++}$ distinctly hexa-(or penta-)co-ordinated, and has high intensity of the double band, as also $\mathrm{Cu}$ tetren ${ }^{++}$has.

The band intensity of $\mathrm{Cu} \mathrm{ptn}_{2}{ }^{++}$is of the same magnitude as for $\mathrm{Cu} \mathrm{en}_{2}{ }^{++}$, while $\mathrm{Cu}$ temeen ${ }_{2}{ }^{++}, \mathrm{Cu} \mathrm{tn}_{2}{ }^{++}$, and $\mathrm{Cu} \mathrm{bdn}_{2}{ }^{++}$are much stronger coloured. In the bis(diamine) complexes, the absorption band vanishes in the infra-red. the values of $\varepsilon$ being:

\begin{tabular}{|c|c|c|c|}
\hline & $800 \mathrm{~m} \mu$ & $900 \mathrm{~m} \mu$ & $1000 \mathrm{~m} \mu$ \\
\hline $\mathrm{Cu} \mathrm{en}_{\mathbf{2}}++$ & 2.7 & 0.7 & 0.3 \\
\hline $\mathrm{Cu} \operatorname{tn}_{\mathbf{z}}++$ & 13.0 & 4.1 & 1.4 \\
\hline Cu ptn ${ }_{2}++$ & 7.2 & 3.4 & 1.5 \\
\hline $\mathrm{Cu}$ temeen $\mathrm{z}_{\mathbf{2}}++$ & 9.6 & 4.0 & 2.4 \\
\hline $\mathrm{Cu} \mathrm{bdn}_{2}++$ & 19.6 & 6.0 & 2.0 \\
\hline $\mathrm{Cu}$ dent+ & 11.5 & 3.4 & 1.0 \\
\hline
\end{tabular}

\section{CHELATE STABILIZATION EFFECTS}

In Table 2, the wavenumbers of the four strong absorption bands of paramagnetic nickel(II) complexes are classified, according to the number of nitrogen atoms in the first co-ordination sphere. The formulae of $\mathrm{Ni} \mathrm{py}_{6}{ }^{++}, \mathrm{Ni}$ ata $\left(\mathrm{NH}_{3}\right)_{2}^{-}, \mathrm{Ni}$ enta $\left(\mathrm{NH}_{3}\right)^{-}$and $\mathrm{Ni}$ enta $\mathrm{CN}^{-3}$ are tentative.

The last complex is classified as a system with three $N$.

It is a rather good approximation except for the highly polarizable anions as $\mathrm{SCN}^{-}, \mathrm{NO}_{2}^{-}$, and $\mathrm{CN}^{-}$to write the spectrochemical series according to the elements alone as:

$$
\mathrm{Br}<\mathrm{Cl}<\mathrm{F}<\mathrm{O}<\mathrm{N}
$$

In the amino-acid complexes, the active atoms in the first co-ordination sphere are $\mathrm{O}$ from carboxyl groups and water and $\mathrm{N}$ from the amine groups. The oxygen atoms are not very different. The oxalate ion is nearly coincident 
with water in the spectrochemical series 4 , but has a similar position among carboxyl groups as ethylenediamine has among the amines. The other carboxyl groups are slightly bathochromic, as found by Linhard and Weigel ${ }^{7}$ and for nickel(II) propionates etc. by Pestemer and Alslev-Klinker ${ }^{44}$. The results reported in this paper show the following spreading of the amines in the spectrochemical series:

$$
\text { py }<\mathrm{NH}_{3}<\operatorname{tn}<\text { bdn }<\left\{\begin{array}{c}
\text { en } \\
\text { temeen } \\
\text { trien } \\
\text { tren }
\end{array}\right\}<\operatorname{den}<\operatorname{ptn}<\operatorname{dip}<\text { phen. }
$$

Already Russell, Cooper and Vosburgh 57 found empirically that the formation constants of nickel(II) amine complexes increase with the hypsochromic effect of the ligand.

It is easily seen from Table 2 that the polydentate amino-acids generally are further removed in the spectrochemical series than interpolated directly from the rule of average environment. Thus, one $\mathrm{N}$ in $\mathrm{Ni}$ ata and two $\mathrm{N}$ in $\mathrm{Ni}$ enta ${ }^{-2}$ function as $2.5 \mathrm{NH}_{3}$ and $4.5 \mathrm{NH}_{3}$, respectively, if the visible band is compared to the spectra of $\mathrm{Ni}\left(\mathrm{NH}_{3}\right)_{n}\left(\mathrm{H}_{2} \mathrm{O}\right)_{6-n}++$ found by $\mathrm{J}$. Bjerrum ${ }^{12}$. Since the crystal field strength is roughly proportional $9,41,45,46$ to $R^{-5}$, where $R$ is the distance to the negative charge of the ligand, this observation can easily be explained by a slightly tighter bonding. It is interesting ${ }^{1}$ that even the anhydrous Co enta ${ }^{-}$is $2.5 \%$ hypsochromic in the first band, compared to Co enta $\mathrm{H}_{2} \mathrm{O}^{-}$. As seen from the method of preparation ${ }^{14}$, the latter complex must be highly thermodynamically unstable in aqueous solution.

Even if $\Delta G$ and $\Delta H$ cannot be calculated from the spectrochemical series, ignoring the many unknown factors in the case of closed-shells as $\mathrm{Zn}^{++}$, considerable correlation can be found between the relative values for $\Delta G$ and $\Delta H$. For example, the differences between negative and neutral ligands are particularly large. The exchange with water of chloride ions has formation constants slightly below 1 , whereas the relative crystal field strength ${ }^{38}$ of $\mathrm{Cl}^{-}$and $\mathrm{H}_{2} \mathrm{O}$ is 0.76 and the corresponding ratio for amines and $\mathrm{H}_{2} \mathrm{O}$ is $\sim 1.3$. Thus, the high formation constants for enta ${ }^{-4}$-complexes are partly due to electrostatic effects.

J. Bjerrum and the author ${ }^{23}$ discussed the ethylenediaminetetraacetates of the divalent ions of the first transition group, $\log K$ varies ${ }^{15}$ from 10.96 for $\mathrm{Ca}^{++}$over 14.04 for $\mathrm{Mn}^{++}$to 16.50 for $\mathrm{Zn}^{++}$. If $\mathrm{Ni}^{++}$had a closed d-shell, $\log K$ would extrapolate 15.5 instead of the observed value 18.62. The stabilization of 2.8 in $\log K$ corresponds to $3.8 \mathrm{kcal} / \mathrm{mole}=1300 \mathrm{~cm}^{-1}$. Analogously, the formation constants for lanthanide-enta complexes vary smoothly from $\log K=15.50$ for $\mathrm{La}$ enta- over 17.37 for $\mathrm{Gd}^{-}$enta ${ }^{-}$to 19.83 for Lu enta-. These half- and closed shell structures represent the standard state of electrostatic behaviour while all the other complexes are stabilized between 0.2 and 0.3 units in $\log K$, due to the smaller influence of the crystal field on $f$ - than on d-electrons.

In Table 4, a series of stabilization energies are compiled for $\mathrm{Fe}^{++}, \mathrm{Co}^{++}$, 。 $\mathrm{Ni}^{++}$and $\mathrm{Cu}^{++}$, when the non-stabilized values of $\log K_{\mathrm{n}}$ are assumed to vary linearly with the number of d-electrons between $\mathrm{Mn}^{++}$and $\mathrm{Zn}^{++}$. Most examples are taken from the article of Schwarzenbach ${ }^{24}$ on the chelate effect, 
Table 4. Crystal field stabilization of complexes of the second half of the first transition group. Most formation constants refer to $20^{\circ} \mathrm{C}$ and the ionic strength $\sim 0.1$. $\varrho$ is the stabilization parameter ${ }^{22}$ valid for regularly octahedral complexes, viz. energy decrease $=0.2$ e $\left(\mathrm{E}_{1}-\mathrm{E}_{2}\right)$. Ref. 63 considers $\mathrm{N}$-substituted iminodiacetates $\mathrm{RN}\left(\mathrm{CH}_{2} \mathrm{COO}^{-}\right)_{2}$, here denoted Rada. The consecutive formation constants are considered in cases, where the formulae indicate the binding of the second or the third ligand.

Ref. No.

Ligands beside water

62 py

24 en

24 en

24 en $_{3}$

24 tren

24 trien

24 penten

59 ata

17 ata,

15 enta

$63 \mathrm{CH}$ ada

$63\left(\mathrm{CH}_{3} \mathrm{ada}\right)_{2}$

$63 \mathrm{C}_{8} \mathrm{H}_{5} \mathrm{ada}$

$63 \mathrm{HOC}_{2} \mathrm{H}_{4} \mathrm{ada}$

63 (HOC $\left.\mathrm{H}_{4} \mathrm{ada}\right)_{2}$

$63 \mathrm{NH}_{2} \mathrm{C}_{2} \mathrm{H}_{4}$ ada $\varrho=$

\begin{tabular}{cc}
\multicolumn{2}{c}{$\log \boldsymbol{K}_{\mathbf{n}}$} \\
$\mathbf{M n}++$ & $\mathrm{Zn}++$ \\
$\mathbf{0 . 1 4}$ & $\mathbf{0 . 9 5}$ \\
$\mathbf{2 . 8}$ & $\mathbf{6 . 0}$ \\
$\mathbf{2 . 1}$ & $\mathbf{3 . 3}$ \\
$\mathbf{0 . 9}$ & $\mathbf{2 . 0}$ \\
$\mathbf{5 . 8}$ & $\mathbf{1 4 . 6}$ \\
$\mathbf{4 . 9}$ & $\mathbf{1 2 . 1}$ \\
$\mathbf{9 . 4}$ & $\mathbf{1 6 . 2}$ \\
$\mathbf{7 . 4 4}$ & $\mathbf{1 0 . 4 5}$ \\
$\mathbf{3 . 7}$ & $\mathbf{3 . 0}$ \\
$\mathbf{1 4 . 0 4}$ & $\mathbf{1 6 . 5 0}$ \\
$\mathbf{5 . 4 0}$ & $\mathbf{7 . 6 6}$ \\
$\mathbf{4 . 1 6}$ & $\mathbf{6 . 4 3}$ \\
$\mathbf{1 . 5 8}$ & $\mathbf{3 . 2 2}$ \\
$\mathbf{5 . 5 5}$ & $\mathbf{8 . 3 3}$ \\
$\mathbf{3 . 7 6}$ & $\mathbf{3 . 6 9}$ \\
$\mathbf{7 . 7 1}$ & $\mathbf{1 1 . 9 3}$ \\
$\mathbf{0}$ & $\mathbf{0}$
\end{tabular}

Stabilization found from the hypothesis of linear variation of $\log K_{n}$ with the number of d-electrons from 5 to 10

\begin{tabular}{|c|c|c|c|}
\hline $\mathrm{Fe}++$ & $\mathrm{Co}++$ & $\mathrm{Ni}++$ & $\mathbf{C u}++$ \\
\hline 0.41 & 0.68 & 1.15 & 1.62 \\
\hline 1.0 & 1.9 & & \\
\hline 1.0 & 2.4 & 3.8 & 6.3 \\
\hline 0.9 & 1.9 & 3.1 & -1.7 \\
\hline 1.2 & 3.5 & 3.7 & 6.0 \\
\hline 1.5 & 3.2 & 4.8 & 9.7 \\
\hline 0.4 & 3.7 & 5.8 & 7.6 \\
\hline 0.8 & 2.0 & 2.0 & 2.8 \\
\hline - & 0.5 & 1.6 & - \\
\hline$\sim 0$ & 1.3 & 3.1 & 2.8 \\
\hline 0.80 & 1.32 & 1.97 & 3.88 \\
\hline 0.76 & 1.24 & 1.70 & 0.85 \\
\hline 0.10 & 0.66 & 0.97 & 3.68 \\
\hline $\mathbf{0 . 6 7}$ & 1.23 & 2.07 & 4.09 \\
\hline & 0.46 & 1.25 & 1.31 \\
\hline 1.25 & $\mathbf{2 . 3 7}$ & 3,50 & 4.82 \\
\hline & $\sim 4$ & 6 & \\
\hline
\end{tabular}

and from the recent measurements by Schwarzenbach, Anderegg, Schneider and Senn ${ }^{63}$ on substituted iminodiacetates $\mathrm{R}\left(\mathrm{CH}_{2} \mathrm{COO}^{-}\right)_{2} \equiv \mathbf{R}$ ada. It is seen that the stabilization for iron(II), cobalt(II), and nickel(II) complexes are roughly proportional to the stabilization parameter ${ }^{22} \varrho, v i z .2,4$ and 6 . In some cases, e.g. the third en or the second $\mathrm{HOC}_{2} \mathrm{H}_{4}$ ada the steric conditions for bonding are better in $\mathrm{Mn}^{++}$than in $\mathrm{Zn}^{++}$, but here also the evolution of stabilization energies is rather regular. On the other hand, the strong tendency of tetragonal distortion in copper(II) complexes produces an enormous stabilization of ligands on the four planar places, e.g. in $\mathrm{en}_{2}$ and trien. The effective value of $\varrho$ for $\mathrm{Cu}^{++}$in Table 4 can exceed the value 10, whereas values $\sim 3$ $v_{\mathrm{Cu}} / v_{\mathrm{Ni}} \sim 5$ might have been expected.

In nickel(II) complexes the crystal field stabilization can be compared to the theoretical value $1.2\left(E_{1}-E_{2}\right)$. However, as seen from Table 2, the value of $\left(E_{1}-E_{2}\right)$ cannot be found accurately from the absorption spectra, since the relative positions of the bands vary some hundred $\mathrm{cm}^{-1}$ in an irregular way. If the energies of the two lowest levels are defined:

$$
{ }^{3} \Gamma_{2}(F)=-1.20\left(E_{1}-E_{2}\right)
$$

- then the Orgel diagram of nickel(II) complexes ${ }^{1}$ can be approximately described by the three other lines in the range of our interest:

$$
\begin{aligned}
& { }^{3} \Gamma_{4}(F)=2800 \mathrm{~cm}^{-1}+0.155\left(E_{1}-E_{2}\right) \\
& { }^{3} \Gamma_{4}(P)=15100 \mathrm{~cm}^{-1}
\end{aligned}
$$

Acta Chem. Scand. 10 (1956) No. 6 
and after correction for the intermixing of triplet character:

$$
{ }^{1} \Gamma_{3}(D)=16500 \mathrm{~cm}^{-1}-1.55\left(E_{1}-E_{2}\right)
$$

These equations demonstrate that either are the term distances to ${ }^{3} P,{ }^{1} D$, and ${ }^{1} G$ decreased from the values, found from the gaseous ion, or other electron configurations are intermixed in the states of the complexes. The former alternative explanation is discussed below in the last section.

If $\left(E_{1}-E_{2}\right)$ is assumed to be the wavenumber of the first band $10100 \mathrm{~cm}^{-1}$ in $\alpha-\mathrm{Ni}$ enta ${ }^{-1}$ and $8500 \mathrm{~cm}^{-1}$ in $\mathrm{Ni}\left(\mathrm{H}_{2} \mathrm{O}\right)_{6}{ }^{++}$the predicted stabilization is 1900 $\mathrm{cm}^{-1}$. The similar numbers are:

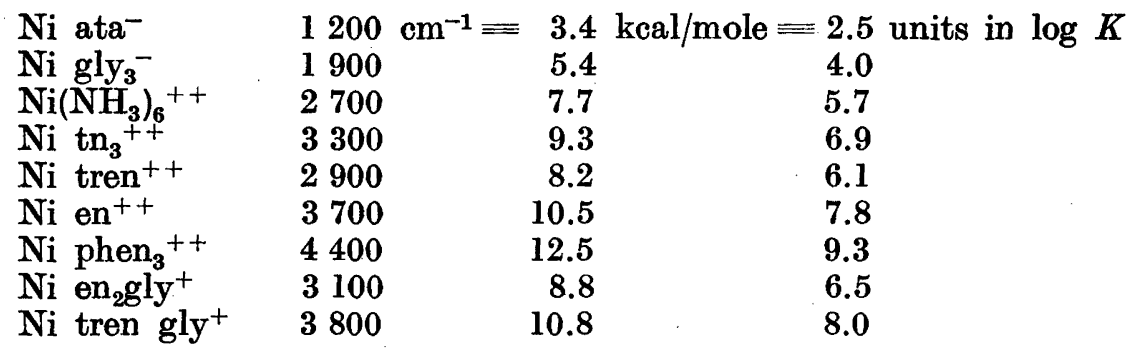

It must be remembered that these quantities are found from the spectra by subtraction of the even larger stabilization of the hexarquo ion, relative to the free $\mathrm{Ni}++$ in vacuo. This quantity is $10200 \mathrm{~cm}^{-1} \equiv 29 \mathrm{kcal} / \mathrm{mole} \equiv(\log K=22)$. Orgel ${ }^{47}$ pointed out that this stabilization can actually be observed as a part $(\sim 5 \%)$ of the absolute heat of hydration of metal ions. I. Poulsen and J. Bjerrum ${ }^{25}$ found $\Delta H=21.0 \mathrm{kcal} / \mathrm{mole}$ for $\mathrm{Ni}\left(\mathrm{NH}_{3}\right)_{6}++, 21.3 \mathrm{kcal} / \mathrm{mole}$ for $\mathrm{Ni} \mathrm{tn}_{3}++$ and $27.9 \mathrm{kcal} / \mathrm{mole}$ for $\mathrm{Ni} \mathrm{en}_{3}++$. If these values are corrected for the stabilization mentioned above, the residual "closed shell"

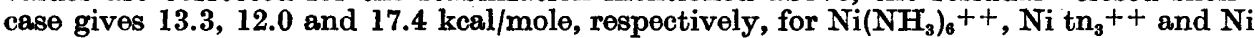
$\mathrm{en}_{3}++$. Besides the d-orbital stabilization, the $\sigma$-bonding of even $\gamma_{1}$ and odd $\gamma_{4}$-electrons $^{48-50}$ may be stronger in the ethylenediamine complexes where the ligands have comparatively smaller distances due to the $\gamma_{3}$-bonding.

The entropy effects in chelate complexes are rather peculiar, inducing the irregular behaviour of $\Delta G$, compared to $\Delta H$. The discussion that follows is concerned only with the importance of chelating number $L$ in reactions of a complex with a polydentate, viz. of the type

$$
\mathrm{Ni} \text { enta-- }+6 \mathrm{NH}_{3} \rightleftharpoons \mathrm{Ni}\left(\mathrm{NH}_{3}\right)_{6}+++e n \mathrm{ea}^{-4}
$$

It is seen from the mass action law that this process is half complete when

$$
\frac{\left[\mathrm{NH}_{3}\right]^{6}}{[\text { enta }]}=\frac{K_{\mathrm{Ni}} \text { enta }}{K_{\mathrm{Ni}}\left(\mathrm{NH}_{3}\right)_{\mathrm{e}}}
$$

Thus, if a buffer concentration of free $[e n t a]=0.01 \mathrm{M}$ is maintained, the free $\left[\mathrm{NH}_{3}\right]$ will be $20 \mathrm{M}$. If a similar experiment is performed with [enta] $=0.01 \mathrm{M}$ and the nickel complex is destroyed with tn or en, respectively, [tn] $=28 \mathrm{M}$ and [en] $=0.24 \mathrm{M}$ are necessary for $50 \%$ decomposition to $\mathrm{Ni} \mathrm{tn}_{3}++$ or $\mathrm{Ni} \mathrm{en} \mathrm{n}_{3}++$. Any formation of mixed complexes, as Ni enta $\mathrm{NH}_{3}^{--}$and $\mathrm{Ni}$ enta en $-\mathrm{N}^{--}$studied above, will of course delay the actual destruction of the bonding between $\mathrm{Ni}^{++}$and enta-4.

Even though $\log K_{1-3}=12.0$ for $\mathrm{Ni} \mathrm{tn}_{3}++$, and $\log K_{1-6}=8.6$ for $\mathrm{Ni}\left(\mathrm{NH}_{3}\right)_{6}++$, it is seen that tn and $\mathrm{NH}_{3}$ in high concentrations are nearly equally effective for decomposing Ni enta--. This is a result of the occurrence of a sixth power term in the mass action law for $\mathrm{NH}_{3}$, but only a third powèr term for tn. Roughly speaking, a dilute solution of a polydentate amine resembles "coarsegrained" aqueous ammonia. The prob-

Acta Chem. Scand. 10 (1956) No. 6 
ability of finding a high number of amine groups ( $L$ groups per molecule) within reach of a certain metal ion is very high, and it is proportional to $\mathrm{C}^{-1}$, whereas, in a monodentate amine like $\mathrm{NH}_{2}$, the corresponding probebility is proportionsl to $C-L$.

Invereely, a polydentate complex is affected very little by dilution of the free ligand.

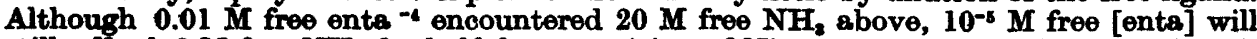
still afford $6 \mathrm{M}$ free $\mathrm{NH}_{3}$ for half decomposition of $\mathrm{Ni}$ ente-, and $10^{-9.8} \mathrm{M}$ ente-4 is sufficient against $1 \mathrm{M} \mathrm{NH}_{3}$. Now, it is essily understood why the yellow diamagnetic $\mathrm{Ni}$ temeen $n_{2}+$ suddenly breaks down at a rather high ammonia concentration:

$$
\mathrm{Ni} \text { temeen, }++6 \mathrm{NH}_{2} \rightleftharpoons \mathrm{Ni}\left(\mathrm{NH}_{3}\right)_{6}+++2 \text { temeen }
$$

with the constants ${ }^{27} \log K_{1-2}=14.68$ for $\mathrm{Ni}$ temeen, ++ and $\log K_{1-6}=8.6$ for $\mathrm{Ni}\left(\mathrm{NH}_{\mathrm{s}}\right)_{8}++, 50 \%$ decomposition is predicted at $\left[\mathrm{NH}_{8}\right]=4.8 \mathrm{M}$ when $[$ temeen] $=0.1 \mathrm{M}$. At slightly higher ammonia concentration, the decomposition is practically complete, owing to the sixth power dependence.

Reversely, the presence of a mixed complex Cu tren en ++ can definitely be proven by the absorption spectrum of a solution, $0.001 \mathrm{M} \mathrm{Cu}, 0.001 \mathrm{M}$ tren, $0.8 \mathrm{M}$ en, which shows the presence of only $\sim 50 \%$ of the copper as $\mathrm{Cu} \theta \mathrm{n}_{2}++$. From the formation constants of $\mathrm{Cu}$ en $\mathrm{n}_{2}+$ and $\mathrm{Cu}$ tren ++ , the constant for the reaction en $+\mathrm{Cu}$ tren $++\rightarrow \mathrm{Cu}$ tren en ++ can be estimated to $\sim 4.10$.

By comparison of ligands with different chelating number $L$, it might be reasonable to choose a acale of apparent activity, proportional to $C^{1 / L}$. Since the standard state of chemical compounds is often chosen as the pure compounds, the formation constants referring to $1 \mathrm{M}$ solutions are from this point of view exaggerated for polydentate ligands. For instence, tren is less affected by dilution than is $\mathrm{NH}_{3}$. J. Bjerrum ${ }^{51}$ pointed out for monodentate ligands that the exchange with water might be treated by defining $\left[\mathrm{H}_{2} \mathrm{O}\right]=55 \mathrm{M}$ in the dilute solutions. Adamson ${ }^{48}$ later demonstrated that most of the $\Delta S^{\prime}$ by chelate formation " vanishes, if a new $\Delta G^{\prime}$ is defined

$$
\Delta G^{\prime}=\Delta G+\Delta \mu R T \ln \mathbf{5 5}
$$

when $\Delta \mu$ is the number of produced moles minus reacted moles, except of the solvent. Actually, the activities of different ligands in dilute solution, compared to the pure compounds, ought to be determined by partial vapour pressures. Adamson's proposal 48 is equivalent to the assumption of activities, proportional to the mole fraction. An alternative proposel will be the moler concentration of the ligand in solution divided with the molar concentration of the pure ligand. In ideal gas mixtures, the two concepts besed on number and partial volumes, are identical, and in dilute solutions the two concepts are only different by a proportionality constant, characteristic for the solvent and the ligand. In stronger solutions, the two proposals may differ somewhat. The molar concentration of the anhydrous, liquid amines at $25^{\circ} \mathrm{C}$ are $38 \mathrm{M} \mathrm{NH}_{3}, 15 \mathrm{M}$ en and $12 \mathrm{M}$ tn. Thus the formation constants of nickel(II) complexes cen be corrected by the factors 38', $15^{3}$, and $12^{3}$, respectively, resulting in $\log K_{1-6}^{\prime \prime}=18.1$ for $\mathrm{Ni}\left(\mathrm{NH}_{3}\right)_{8}++, \log K_{1-3}^{\prime \prime}=21.8$ for $\mathrm{Ni} \mathrm{en}_{\mathrm{a}}++$ and $\log K_{1-3}^{\prime \prime}=15.3$ for $\mathrm{Ni} \mathrm{tn}_{\mathrm{s}}++$. By this method, there appear small res1dual entropy effects ${ }^{25}$, and the crystal field stabilization in $\Delta H$ will of course still subsist in the values of $\Delta Q^{\prime \prime}$, corresponding, e.g., to the predicted difference 2.1 between $\log K_{1-\bullet}$ for $\mathrm{Ni}\left(\mathrm{NH}_{3}\right)_{6}++$ and $\log \bar{K}_{1-3}$ for $\mathrm{Ni}$ on ${ }^{++}$.

\section{THE INTERMIXING OF SINGLET AND TRIPLET LEVELS BY INTERMEDIATE COUPLING}

The validity of sharply defined total spin $S$ and total angular moment $L$ in the free atoms and ions, corresponding ${ }^{2}$ to $S$. and $\Gamma_{n}$ in crystal fields, is weakened by increasing values ${ }^{52}$ of Landé's multiplet factor $\zeta_{\mathrm{nl}}$. In systems in crystal fields, states with the same $\Gamma_{J}$ (found from the internal vector product $^{16}$ of $C(S)$ and $C\left(\Gamma_{\mathrm{n}}\right)$ ) are intermixed with nondiagonal elements of energy 


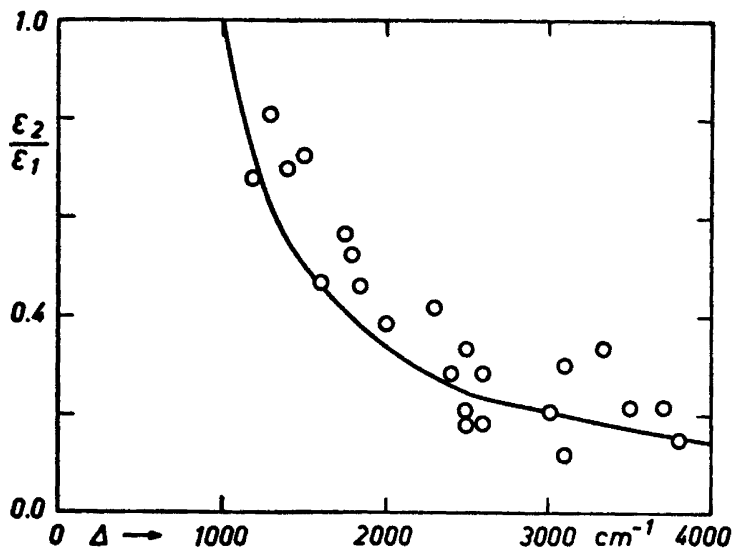

Figure 2. The ratio $\varepsilon_{2} / \varepsilon_{1}$ between the directly observed heights of the two first absorption bands of nickel(II) complexes as function of the difference $\Delta$ between the wavenumbers of the two maxima. The curve represents the function $\frac{\alpha}{1-a}$ with $a=\frac{500 \mathrm{~cm}^{-1}}{\Delta}$ discussed in the text.

$=k \zeta_{\mathrm{n}}$, where the constants $k$ are not very different from 1 . Thus, the usual description of levels in $\mathrm{d}^{\mathrm{n}}$-systems as having definite $S$ and $\Gamma_{\mathrm{n}}$ breaks down, when $k \zeta_{\mathrm{nl}}$ is sufficiently large ${ }^{1}$ and the distance $\Delta$ between the interacting levels small. The intermixing in the squares of the wavefunctions is approximately $\left(\frac{k \zeta_{\mathrm{nl}}}{\Delta}\right)^{2}$.

The most conspicuous case ${ }^{1}$ of intermixing of $S$ in the nickel(II) complexes occurs between the lowest singlet level ${ }^{1} \Gamma_{3}(D)$ and the two lowest excited triplet levels ${ }^{3} \Gamma_{5}(F)$ and ${ }^{3} \Gamma_{4}(F)$ with the values of $k \zeta_{\mathrm{nl}}=500 \mathrm{~cm}^{-1}$ and $800 \mathrm{~cm}^{-1}$, respectively. The numerical results of Tables 1 and 2 are used in Fig. 2 to estimate the former intermixing. The oscillator strength $P$ is divided between the two interacting levels proportional to their triplet character $(S=1)$ since the groundstate for the transition has $S=1$ to a high degree of precision. But the ratio between the values of $P$ for the two components is not easily accessible from the measurements. Rather, it is assumed that the obser$\operatorname{ved}$ maximum $\varepsilon_{\mathrm{n}}$ is proportional to the numerical value of intermixing $\alpha, v i z$.

$$
\frac{\varepsilon_{2}}{\varepsilon_{1}}=\frac{\alpha}{1-\alpha} \text { with } \alpha=\frac{k \zeta_{\mathrm{nl}}}{\Delta}
$$

This is equivalent to assume the half-widths of the bands to be also proportional to $\varepsilon_{n}$. This is a good approximation, since the pure singlet bands ${ }^{1} \Gamma_{3}(D)$ are very narrow.

Fig. 2 gives the ratio $\varepsilon_{2} / \varepsilon_{1}$ as function of the distance $\Delta$ between the two maxima. Further the curve for the function $\frac{\alpha}{1-\alpha}$ with $k \zeta_{\mathrm{nl}}=500 \mathrm{~cm}^{-1}$ is given. It is seen to represent the somewhat scattered points reasonably well. 
The influence of the second triplet level ${ }^{3} \Gamma_{4}(F)$ is important for large values of $\Delta$ (over $2000 \mathrm{~cm}^{-1}$ ) raising the degree of intermixing. On the other side, the non-vanishing half width for $\alpha \rightarrow 0$ should decrease the position of the righthand side points.

The statistical distribution of the points of mixed complexes demonstrates that no particular deviation from cubic symmetry is necessary for making $k \zeta_{n 1}$ large. Fig. 2 demonstrates also the lower limit of $\Delta=2 k \zeta_{n 1}$. The two bands are actually repulsed from each other by this impenetrable barrier. $\mathrm{Mr}$. C. E. Schäffer ${ }^{53}$ has found a similar variation of relative intensities of quartets and doublets with $\Delta$ in chromium(III) complexes. Also iridium(III) complexes ${ }^{38}$ prove that $k \zeta_{\mathrm{nl}}$ is rather invariant $\left(=2000 \mathrm{~cm}^{-1}\right)$ in so different ions as $\mathrm{IrBr}_{6}-, \mathrm{IrCl}_{6}^{-}, \operatorname{Ir}\left(\mathrm{NH}_{3}\right)_{5} \mathrm{Cl}^{++}, \mathrm{Ir} \mathrm{en}_{3}{ }^{+++}$but here $\Delta$ is nearly constant $\left(=7000 \mathrm{~cm}^{-1}\right)$ as function of the crystal field strength, because the singlet and triplet level belong to the same electron configuration ${ }^{31}$ of $\gamma_{\mathrm{n}}$.

The other singlet levels of nickel(II) give much lower intensities to the bands. Therefore, it is necessary to measure strong solutions of pure complexes, and the detection is often impossible in the ranges of the triplet bands. Besides ${ }^{1} \Gamma_{3}(D)$, the two levels ${ }^{1} \Gamma_{5}(D)$ and ${ }^{1} \Gamma_{1}(G)$ should be the next excited singlets, as discussed by Tanabe and Sugano ${ }^{54}$, Ballhausen and Klixbüll Jørgensen ${ }^{16}$, and Orgel ${ }^{49}{ }^{1} \Gamma_{3}(D)$ and ${ }^{1} \Gamma_{1}(G)$ have the configuration $\gamma_{5}^{6} \gamma_{3}{ }^{2}$ common ${ }^{31}$ with the groundstate ${ }^{3} \Gamma_{2}(F)$ and thus should produce narrow bands ${ }^{54,55}$, while ${ }^{1} \Gamma_{5}(D)$ analogous to ${ }^{1} \Gamma_{4}(G),{ }^{3} \Gamma_{5}(F)$ and ${ }^{3} \Gamma_{4}(F)$ in strong crystal fields are $\gamma_{5}^{5} \gamma_{3}{ }^{3}$ with broader transitions from the groundstate. The concept of a single distribution of electrons in molecular orbitals seems nevertheless to be rather inadequate ${ }^{50}$ for the description of a given level $\left(S, \Gamma_{n}\right)$.

Already Gielessen ${ }^{56}$ found a great number of small bands in solid salts of $\mathrm{Ni}\left(\mathrm{H}_{2} \mathrm{O}\right)_{6}{ }^{++}$. In solutions, small bands are found ${ }^{49}$ at $18400 \mathrm{~cm}^{-1}$ and 22000 $\mathrm{cm}^{-1}$. In $\mathrm{Ni} \mathrm{en}_{3}{ }^{++}$, a weak band can be distinguished at $24000 \mathrm{~cm}^{-1}$ in Ref. 40, Fig. 5. It is not easily decided from the half-widths, which band is the "narrow" ${ }^{1} \Gamma_{1}(G)$, but there is some evidence that it is the band at $18400 \mathrm{~cm}^{-1}$ in the hexaaquo ion, contrary to primitive electrostatic calculations ${ }^{16}$. It can interact ${ }^{1}$ by intermediate coupling with ${ }^{3} \Gamma_{4}$, but not with ${ }^{3} \Gamma_{5}$. While most of the absorption bands in Table 1 are very regular, and do not exhibit signs of tetragonal splitting except the fourth band of $\mathrm{Ni}^{2 t a_{2}}{ }^{-4}$, there is a tendency of the third band to have a shoulder towards lower wavenumbers (see the half-widths in $\mathrm{Ni}$ en gly $_{2}, \mathrm{Ni}$ enta $\mathrm{NH}_{3}-, \alpha-\mathrm{Ni}$ enta-, $\mathrm{Ni}$ ata gly and $\mathrm{Ni} \mathrm{ata}^{-}$). While this may very well depend on tetragonal splitting and in a few cases be due to presence of more isomers, it is quite suspicious that the phenomenon prevails in a narrow range of the Orgel diagram near $\left(E_{1}-E_{2}\right)=$ $10000 \mathrm{~cm}^{-1}$. It cannot be excluded that ${ }^{1} \Gamma_{1}(G)$ is going down in the Orgel diagram along a line of the type $23000 \mathrm{~cm}^{-1}-1.7\left(E_{1}-E_{2}\right)$.

\section{THE DECREASE OF THE PARAMETERS OF ELECTROSTATIC INTERACTION BETWEEN d-ELECTRONS IN COMPLEXES}

For a complex with regularly octahedral configuration, the energy levels can be given in the Orgel diagram as function of the crystal field strength $\left(E_{1}-E_{2}\right)$. Tanabe and Sugano ${ }^{54}$ and Owen ${ }^{48}$ emphasized that term differen- 
Table 5. Crystal field strength $\left(\mathrm{E}_{1}-\mathrm{E}_{2}\right)$ and effective term distances for various nickel (II) complexes. The value of $\left(\mathrm{E}_{1}-\mathrm{E}_{2}\right)$ is derived from $\nu_{1}$ and the energies $\left({ }^{3} \mathbf{P}\right)$ and $\frac{4}{7}\left({ }^{1} \mathrm{D}\right)+\frac{3}{7}$ $\left({ }^{1} \mathrm{G}\right)$ from $v_{3}+v_{4}$ and $v_{2}$, respectively. In all cases, the values of $v_{\mathrm{n}}$ from Table 2 are cor. rected for effects of intermediate coupling (important for $v_{1}$ and $\nu_{2}$ ) and for asymmetry of the bands (usually significant for $\nu_{3}$ ). Finally are given the calculated and observed values of the perturbation energy $\Delta \mathrm{E}$ between ${ }^{3} \Gamma_{4}(\mathrm{~F})$ and ${ }^{3} \Gamma_{4}(\mathrm{P})$, as defined $p .908$. All the energies are given in the unit $\mathrm{cm}^{-1}$.

\begin{tabular}{|c|c|c|c|c|c|}
\hline Complex & $\left(E_{1}-E_{2}\right)$ & $\left({ }^{3} P\right)=15 B$ & $\begin{array}{l}\frac{4}{7}\left({ }^{1} D\right)+\frac{3}{7}\left({ }^{1} G\right) \\
\quad=8 B+2 C\end{array}$ & $\Delta E$, calc. & $\Delta E$, obs. \\
\hline Free $\mathrm{Ni}++$ & 0 & 16900 & 17900 & - & - \\
\hline $\mathrm{Ni}\left(\mathrm{H}_{2} \mathrm{O}\right)_{6}++$ & 8500 & 14100 & 14800 & 1080 & 1000 \\
\hline Niata- & 9500 & 12800 & 13300 & 1690 & 1400 \\
\hline$a-N i e n t a^{--}$ & 10100 & 13000 & 12700 & 1980 & 1300 \\
\hline $\mathrm{Ni} \mathrm{gly}_{3}^{-}$ & 10100 & 13900 & 13100 & 1730 & 1600 \\
\hline $\mathrm{Ni} \mathrm{py}_{6}++(?)$ & 10200 & 13000 & 13500 & 1910 & 1900 \\
\hline $\mathrm{Ni}$ enta $\mathrm{NH}_{3}^{--}$ & 10200 & 13500 & 12700 & 1950 & 1200 \\
\hline $\mathrm{Ni}$ ata $_{2}^{-4}$ & 10400 . & 13400 & 13000 & 1900 & 1900 \\
\hline $\mathrm{Ni}$ on $\mathrm{gly}_{2}$ & 10700 & 13500 & 12800 & 2060 & 1750 \\
\hline $\mathrm{Ni}\left(\mathrm{NH}_{3}\right)_{6}++$ & 10800 & 13400 & 13100 & 2380 & 1950 \\
\hline $\mathrm{Ni}$ on glyt & 11300 & 12600 & 12200 & 2460 & 2450 \\
\hline $\mathrm{Ni} \operatorname{tren}\left(\mathrm{H}_{2} \mathrm{O}\right)_{2}++$ & 11300 & 11700 & 12000 & 2720 & 2550 \\
\hline $\mathrm{Ni} \operatorname{tn}_{3}++$ & 11400 & 11900 & 12000 & 2640 & 2650 \\
\hline $\mathrm{Ni} \mathrm{en}_{3}++$ & 11600 & 12600 & 12000 & 2590 & 2550 \\
\hline $\mathrm{Ni} \operatorname{ptn}_{2}++$ & 11700 & 12800 & 12000 & 2700 & 2400 \\
\hline $\mathrm{Ni} \operatorname{tren}\left(\mathrm{NH}_{3}\right)_{2}++$ & 11700 & 11300 & 12000 & 3030 & 2900 \\
\hline $\mathrm{Ni}$ tren ent+ & 11700 & 12600 & 11800 & 2720 & 2400 \\
\hline $\mathrm{Ni}$ tren gly + & 11800 & 11500 & 11900 & 2500 & 2500 \\
\hline
\end{tabular}

ces might also change in complexes from the values for the gaseous ion. Thus, it might be necessary to apply more than one parameter in the Orgel diagram. Actually, the agreement with observed absorption bands can be highly improved by the assumption of decreased term distances in the complexes. Especially, the decrease is larger for many anion complexes than for complexes with neutral ligands.

The energy differences between multiplet terms of a given $\mathrm{d}^{\mathrm{n}}$-configuration can be expressed as multipla of the Slater-Condon-Shortley ${ }^{52}$ parameters $F_{2}$ and $F_{4}$. Racah ${ }^{64}$ applies the linear combinations $B=F_{2}-5 F_{4}$ and $C=35 F_{4}$. In nickel(II)complexes, the distance from the ground term ${ }^{3} F$ to the other triplet term ${ }^{3} P$ is $15 B$. Table 5 gives this distance inferred from the diagonal sum rule:

$$
v_{3}+v_{4}=3\left(E_{1}-E_{2}\right)+\left({ }^{3} P\right)
$$

The wavenumbers $\nu_{3}$ and $v_{4}$ of the third and fourth absorption band are corrected for asymmetry by taking the average of $v_{n}-\delta(-)$ and $v_{n}+\delta(+)$ from Table 1. It is seen from Table 5 that $B$ actually decreases to $\sim 70 \%$ of the original value, but not as a monotoneous function of $\left(E_{1}-E_{2}\right)$. Since three excited triplet levels occur in paramagnetic nickel(II)complexes, it is of interest to see whether the two parameters $\left(E_{1}-E_{2}\right)$ and $B$ are sufficient for their description. The two ${ }^{3} \Gamma_{4}$ levels have energies, which are the roots $E_{\mathrm{a}}$ and $E_{\mathrm{b}}$ of the secular determinant ${ }^{49}$ : 


$$
\left|\begin{array}{ll}
E_{33}-E & E_{34} \\
E_{34} & E_{4}-E
\end{array}\right|=0
$$

with $E_{33}=0.6\left(E_{1}-E_{2}\right) ; E_{44}=\left({ }^{3} P\right)$; and $E_{34}=0.4\left(E_{1}-E_{2}\right)$.

We define the perturbation energy $\Delta E$ by $E_{\mathrm{a}}=E_{33}-\Delta E$ and $E_{\mathrm{b}}=E_{44}+$ $\Delta E$. The observed and calculated values of $\Delta E$ are seen to agree except for the ethylenediaminetetraacetate complexes.

Finally, Table 5 gives the values of $\frac{4}{7}\left({ }^{1} D\right)+\frac{3}{7}\left({ }^{1} G\right)=8 B+2 C$, which is the asymptotical ${ }^{16,54}$ energy of ${ }^{1} \Gamma_{3}(D)$ above ${ }^{8} \Gamma_{2}\left(F^{\prime}\right)$. The wavenumber $\nu_{2}$ is correoted for the influence of intermediate coupling. It is seen that $C$ decreases slightly more than $B$ in the complexes. This can be interpreted as an expansion of the 3d-wavefunction into a larger volume. For isomorphous wavefunctions, both $F_{2}$ and $F_{4}$ are inversely proportional to the average radius; whereas in the case of spreading from, e.g., the concentration on a spherical surface, $F_{2} / F_{4}$ increases with resulting decrease of the ratio $C / B$. Owen ${ }^{48}$ assumes that the decrease of $B$ in complexes is caused by covalent bonding. However, it is not easily decided if this is the only possible explanation. It is interesting to compare nickel(II) with other metal ions. Thus, Schäffer ${ }^{53}$ investigates many chromium(III) complexes, where the distance $\sim 12 B$ between ${ }^{4} \Gamma_{5}(F)$ and - $\Gamma_{4}(P)$ implies values of $B$ in the range $500-750 \mathrm{~cm}^{-1}$ while $B=950 \mathrm{~cm}^{-1}$ in $\mathrm{Cr}^{+++}$. The distance $\sim 16 B$ between ${ }^{1} \Gamma_{4}$ and ${ }^{1} \Gamma_{5}$ of cobalt(III) complexes ${ }^{54}$ gives slightly smaller values of $B$. Diamagnetic $d^{6}$-systems of the two next transition groups ${ }^{38}$ have even smaller values of $B: \mathrm{RhCl}_{6}{ }^{-3}$ has $310 \mathrm{~cm}^{-1}$, $\mathrm{Rh}\left(\mathrm{NH}_{3}\right)_{6}+++$ and $\mathrm{Rhen}_{3}{ }^{+++}$both $400 \mathrm{~cm}^{-1}$, and $\operatorname{IrCl}_{6}^{-3}$ has $B=250 \mathrm{~cm}^{-1}$. On the other hand, manganese(II) complexes have values of $B$ and $C$, which are not much less than the values for $\mathrm{Mn}^{++}$. Thus, only $7 \%$ decrease is observed ${ }^{55}$ in $\mathrm{Mn}\left(\mathrm{H}_{2} \mathrm{O}\right)_{6}{ }^{++}$and $11 \%$ in $\mathrm{Mn}^{+}$enta- ${ }^{-}$, as will be discussed in the third paper of this series. While it might seem somewhat unsatisfactory to describe four absorption bonds of nickel(II) complexes by three parameters, $\left(E_{1}-E_{2}\right), B$, and $C$, ten bands of manganese(II) can also be described by the three parameters. The orystal field theory can be applied to all $\mathrm{d}^{\mathrm{n}}$-systems, giving a much more unified picture than earlier sharp distinctions between "ionic" and "covalent" complexes.

\section{EXPERIMENTAL}

The absorption spectra were measured in the range $800-325 \mathrm{~m} \mu$ with a Cary recording spectrophotometer at room temperature, $20^{\circ} \mathrm{C}$, and in the range $800-1080 \mathrm{~m} \mu$ with a Beckman DU spectrophotometer. $1 \mathrm{~cm}$ absorption cells were always used, and the measurements in the infra-red performed with a maximum interval of $20 \mathrm{~m} \mu$.

$1.07 \mathrm{M} \mathrm{Ni}\left(\mathrm{NO}_{3}\right)_{2}$ (AnalaR) and $0.050 \mathrm{M} \mathrm{CuSO}$, were transferred to measuring flasks with a Krogh's $1.00 \mathrm{ml}$ syringe pipette. The ligands were added in solutions from microburettes, and finally diluted with water. In cases of rarer ligands, $10 \mathrm{ml}$ measuring flasks were shown to be sufficiently precise for the messurement of the spectra.

$H_{4}$ enta (complexon II) and $H_{3} a t a$ (Prof. Schwarzenbach's sample and complexon I) were dissolved in water with 2 and 1.5 moles of Merck's $\mathrm{Na}_{2} \mathrm{CO}_{3}$ per mole amino-acid, respectively, and diluted.

tren $\mathrm{H}_{3} \mathrm{Cl}_{3}$, ptn $\mathrm{H}_{3} \mathrm{Cl}_{3}$ and temeen $\mathrm{H}_{2} \mathrm{Cl}_{2}$ were weighed off and dissolved in stoichiometric amounts of $\mathrm{NaOH}$ solution.

$\mathrm{H}$ gly was dissolved with 1 equiv. of $\mathrm{KOH}$ in water. 
Dilute solutions of ammonia and ethylenediamine (Merck's No. 946) were titrated. tn and bdn were supplied by Shapley Co. den was purified from the commercial product by fractional distillation and tetren by standing two weeks of the $1 \mathrm{M}$ solution with norite coal, removing the yellow colour. $\mathrm{Cu}$ den $\mathrm{NH}_{3}++$ was messured in $0.4 \mathrm{M} \mathrm{NH}_{3}$ and $\mathrm{Ni}$ tetren $\mathrm{NH}_{3}++$ in $1 \mathrm{M}$ and $2 \mathrm{M} \mathrm{NH}$.

Redistilled pyridine was kindly furnished by $\mathrm{Mr}$. F. Woldbye.

The concentration of nickel(II) was usually $0.107 \mathrm{M}$, but more dilute solutions $(0.02 \mathrm{M}$ ) were made of $\mathrm{Ni}$ ente-- and addition compounds for measurement of the high first band.

The concentration of copper(II) solutions varied between $0.04 \mathrm{M}$ and $0.01 \mathrm{M}$.

Acknowledgments. I am very much indebted to Professor Jannik Bjerrum for his interest in the work. Further, I thank Mr. C. E. Schäffer for valuable discussions and information about the analogies with absorption spectra of chromium(III) and cobalt(III) complexes. Finally, I express my gratitude to Professor G. Schwarzenbach, Zürich, for samples of $\mathrm{H}_{8}$ ate, ptn $\mathrm{H}_{3} \mathrm{Cl}_{8}$ and tren $\mathrm{H}_{3} \mathrm{Cl}_{3}$, and to Professor Fred Basolo, Northwestern University, Evanston, Illinois, for samples of temeen $\mathrm{H}_{2} \mathrm{Cl}_{2}, \mathrm{Ni}$ temeen $\mathbf{n}_{2} \mathrm{Cl}_{2}$ and of tren $\mathrm{H}_{3} \mathrm{Cl}_{3}$, and to Dr. F. G. Mann, Cambridge, for samples of $\mathrm{Ni} \mathrm{ptn}_{2} \mathrm{SO}_{4}$ and several trencomplexes presented to this study of energy levels.

\section{REFERENCES}

1. Jørgensen, C. Klixbüll Acta Chem. Scand. 9 (1955) 1362.

2. Bethe, H. Ann. Physik [5] 3 (1929) 133.

3. Mead, A. Trans. Faraday Soc. 38 (1934) 1055.

4. Tsuchida, R. Bull. Chem. Soc. Japan 13 (1938) 388, 436 and 471.

5. Mathieu, J.-P. Bull. soc. chim. France [5] 3 (1935) 463, 476 and 5 (1938) 105.

6. Linhard, M. and Wiegel, M. Z. anorg. Chem. 266 (1951) 49.

7. Linhard, M. and Weigel, M. Z. anorg. Chem. 264 (1951) 321.

8. Jonassen, H. B., Reeves, R. E. and Segal, L. J. Am. Chem. Soc. 77 (1955) 2667 and 2748.

9. Belford, R. L. Bonding and Spectra of Metal Chelates. Thesis 1955. University of California UCRL - 3051.

10. Basolo, F., Ballhausen, C. J. and Bjerrum, J. Acta Chem. Scand. 9 (1955) 810.

11. Jørgensen, C. Klixbüll Acta Chem. Scand. 10 (1956) in press.

12. Bjerrum, J. Metal Ammine Formation in Aqueous Solution. Thesis, Copenhagen 1941.

13. Ballhausen, C. J. Kgl. Danske Videnskab. Selskab, Mat.-fys. Medd. 29 (1955) No. 8.

14. Schwarzenbach, G. Helv. Chim. Acta 32 (1949) 839.

15. Schwarzenbach, G., Gut, R. and Anderegg, G. Helv. Chim. Acta 37 (1954) 937.

16. Ballhausen, C. J. and Jørgensen, C. Klixbüll Kgl. Danske Videnskab. Selskab, Mat.-fys. Medd. 29 (1955) No. 14.

17. Schwarzenbach, G. and Biedermann, W. Helv. Chim. Acta 31 (1948) 331.

18. Jørgensen, C. Klixbüll Acta Chem. Scand. 9 (1955) 405.

19. Cox, E. G. and Webster, K. C. Z. Kristallogr. 92 (1935) 478.

20. Jonassen, H. B. and Douglas, B. E. J. Am. Chem. Soc. 71 (1949) 4094.

21. Flood, H. and Lorås, V. Tidsskr. Kjemi, Bergvesen Met. 6 (1945) 83.

22. Jørgensen, C. Klixbüll and Bjerrum, J. Acta Chem. Scand. 9 (1955) 180.

23. Bjerrum, J. and Jørgensen, C. Klixbüll Rec. trav. chim. 75 (1956) 658.

24. Schwarzenbach, G. Helv. Chim. Acta 35 (1952) 2344.

25. Poulsen, I. and Bjerrum, J. Acta Chem. Scand. 9 (1955) 1407.

26. Prue, J. E. and Schwarzenbach, G. Helv. Chim. Acta 33 (1950) 995.

27. Basolo, F., Chen, Y. T. and Murmann, R. K. J. Am. Chem. Soc. 76 (1954) 956.

28. Jørgensen, C. Klixbüll and Bjerrum, J. Nature 175 (1955) 426.

29. Bjerrum, J. and Lamm, C. G. Acta Chem. Scand. 4 (1950) 997.

30. Jørgensen, C. Klixbüll Acta Chem. Scand. 8 (1954) 1502.

31. Jørgensen, C. Klixbüll Acta Chem. Scand. 9 (1955) 116.

32. Bjerrum, J., Ballhausen, C. J. and Jørgensen, C. Klixbüll Acta Chem. Scand. 8 (1954) 1275.

33. Jørgensen, C. Klixbüll Acta Chem. Scand. 8 (1954) 175.

34. Bjerrum, J., Adamson, A. W. and Bostrup, O. Acta Chem. Scand. 10 (1956) 329.

Acta Chem. Scand. 10 (1956) No. 6 
35. Bennett, M. C. and Schmidt, N. O. Trans. Faraday Soc. 51 (1955) 1412.

36. Schwarzenbach, G. and Heller, J. Helv. Chim. Acta 34 (1951) 576.

37. Duke, F. R. and Courtney, W. G. J. Phys. Chem. 56 (1952) 19.

38. Jørgensen, C. Klixbüll Acta Chem. Scand. 10 (1956) 500.

39. Pfeiffer, P. and Schmitz, E. Z. anorg. Chem. 258 (1949) 247.

40. Jørgensen, C. Klixbüll Acta Chem. Scand. 8 (1954) 1495.

41. Ballhausen, C. J. Kgl. Danske Videnskab. Selskab, Mat.-fys. Medd. 29 (1954) No. 4.

42. Prue, J. E. and Schwarzenbach, G. Helv. Chim. Acta 33 (1950) 963.

43. Adamson, A. W. J. Am. Chem. Soc. 76 (1954) 1578.

44. Pestemer, M. and Alslev-Klinker, A. Z. Elektrochem. 53 (1949) 387.

45. Polder, D. Physica 9 (1942) 709.

46. Ilse, F. E. and Hartmann, H. Z. physik. Chem. 197 (1951) 239.

47. Orgel, L. E. J. Chem. Soc. 19524756.

48. Owen, J. Proc. Roy. Soc. London 227 A (1955) 183.

49. Orgel, L. E. J. Chem. Phys. 23 (1955) 1004 and 1819.

50. Jørgensen, C. Klixbüll Acta Chem. Scand. 10 (1956) 518.

51. Bjerrum, J. Chem. Revs. 46 (1950) 381.

52. Condon, E. U. and Shortley, G. H. Theory of Atomic Spectra. Cambridge 1953.

53. Schäffer, C. E. Acta Chem. Scand. To be published.

54. Tanabe, Y. and Sugano, S. J. Phys. Soc. Japan 9 (1954) 753 and 766.

55. Orgel, L. E. J. Chem. Phys. 23 (1955) 1824 and 1958.

56. Gielessen, J. Ann. Physik [5] 22 (1935) 537.

57. Russell, C. D., Cooper, G. R. and Vosburgh, W. G. J. Am. Chem. Soc. 65 (1943) 1301.

58. Plumb, R. C., Martell, A. E. and Bersworth, F. C. J. Phys. Chem. 54 (1950) 1208.

59. Schwarzenbach, G. and Freitag, E. Helv. Chim. Acta 34 (1951) 1492.

60. Schwarzenbach, G., Ackermann, H., Maissen, B. and Anderegg, G. Helv. Chim. Acta 35 (1952) 2337.

61. Schwarzenbach, G. and Ackermann, H. Helv. Chim. Acta 30 (1947) 1798.

62. Bjerrum, J. Tables of Complexity Constants... (In press).

63. Schwarzenbach, G., Anderegg, G., Schneider, W. and Senn, H. Helv. Chim. Acta 38 (1955) 1147.

64. Racah, G. Phys. Rev. 62 (1942) 438.

65. Mann, F. G. and Pope, W. J. J. Chem. Soc. 19262675 and 2681.

66. Mann, F. G. Symposium on Co-ordination Chemistry. Copenhagen 1953, p. 71.

67. Haendler, H. M. J. Am. Chem. Soc. 64 (1942) 686.

Received March 2, 1956. 